This item was submitted to Loughborough's Research Repository by the author.

Items in Figshare are protected by copyright, with all rights reserved, unless otherwise indicated.

\title{
Quantifying accident risk and severity due to speed from the reaction point to the critical conflict in fatal motorcycle accidents
}

PLEASE CITE THE PUBLISHED VERSION

https://doi.org/10.1016/j.aap.2020.105548

PUBLISHER

Elsevier

VERSION

AM (Accepted Manuscript)

\section{PUBLISHER STATEMENT}

This paper was accepted for publication in the journal Accident Analysis and Prevention and the definitive published version is available at https://doi.org/10.1016/j.aap.2020.105548.

LICENCE

CC BY-NC-ND 4.0

\section{REPOSITORY RECORD}

Murphy, Peter, and Andrew Morris. 2020. "Quantifying Accident Risk and Severity Due to Speed from the Reaction Point to the Critical Conflict in Fatal Motorcycle Accidents". Loughborough University. https://hdl.handle.net/2134/12156480.v1. 


\section{Critical Conflict}

in

Fatal Motorcycle Accidents

Peter Murphy ${ }_{1}$, Transport Safety Research Group, Design School, Loughborough University, UK (corresponding author) and Andrew Morris, Transport Safety Research Group, Design School, Loughborough University, Loughborough, UK (a.p.morris@1boro.co.uk)

Abstract

14 In fatal road vehicle accidents motorcycles are overrepresented per vehicle kilometre travelled.

15 Fatal accidents involving motorcycles contain mode specific characteristics, and in common with

16 fatal accidents involving all road users, speed typically presents as a significant contributory

17 factor. The aim of the present study is to provide quantitative estimates for the contribution of 18 speed in situations commencing from the reaction location to the safety critical event involving

19 a motorcyclist and resulting in a fatal accident. The contribution of speed to the resulting accident

20 risk and accident severity is considered from this reaction point. A speed-squared versus stopping

21 distance domain, termed the severity-risk space, is examined to determine the accident measures.

22 The defined accident measures, namely, accident risk, accident severity and accident severity risk

23 are calculated for sixteen fatal accidents from a police dataset of recent UK motorcycle accidents.

24 The estimates of the defined measures are provided in terms relative to values estimated for the 1 The author was on sabbatical leave in 2018 from Dept. of Physics, University of Limerick, Limerick, Ireland when the primary analysis was carried out. 
25 vehicle travelling at the speed limit at the safety critical event. The relative accident risk in response to a safety critical situation shows a partial speed dependent reaction phase and a speedsquared dependent braking phase and ranges from 1.3 to 2.8 . The speed-squared dependent accident severity measure ranges from 1.4 to 7.3 at pre-impact speeds. The relative accident severity risk shows speed squared to speed cubed dependency components during the reaction phase and a speed to the power of four dependent braking phase and ranges from 2.3 to 22.8 . In eight cases the collision would have been avoided had the motorcyclist been travelling at the speed limit at the critical point and in the other eight cases the relative accident severity at impact ranged from 1.4 to 17.2 . The speed-squared versus stopping distance domain provides an informative parameter space for considering the accident risk and accident severity dimensions of road user accidents.

Keywords

motorcycle accident, speed, kinetic energy, stopping distance, accident risk, accident severity

\section{Introduction}

Road safety remains a major societal issue within the European Union. In 2016 25,600 people 45 died on the roads in Europe (ERSO Report, 2018). Road fatalities have generally been falling within the EU in recent times, although there are variations between Member States. Over the past 25 years, most Member States have achieved an overall reduction, some more than 50\% (Morris et al., 2018). During this period, research on road safety and accident prevention has predominantly focused on protecting car occupants, with significant results. However, at the 
same time the number of fatalities and injuries amongst other categories of road users has not

51 fallen to the same extent, indeed, in some cases, they have risen. $\underline{\text { uulnerable road users (VRUs) }}$ are a priority and represent a real challenge for researchers working on accident prevention. Accidents involving VRUs comprised approximately $48 \%$ of all fatalities in the EU during 2016, with motorcyclists comprising 14\% of all fatalities (3644 fatalities, ERSO Report, 2018). Motorcycle accidents with fatal outcomes are the focus of the present study.

Motorcycles are appealing to road users for a variety of reasons and their use has continued to increase over the years. One of the reasons for their appeal, in terms of mobility, is their compact size which permits them to park in small spaces. Their size also aids motorcycle riders to easily move in and out of traffic. Motorcycles have low mass and aerodynamic drag compared to cars,

60 involve low $\mathrm{CO}_{2}$ emissions, and are therefore a fuel efficient modal choice. They are attractive

61 for leisure trips and many returning or new users with disposable income are (re-)discovering this activity (Stutts, et al., 2004; Dischinger, et al. 2006).

However, there are disadvantages; e.g. they move in traffic environments (including high speed limit environments) predominately populated with larger mass vehicles without the protective structure and devices of car drivers. Having two wheels means that motorcycle riders can lose control more easily than car users; control can be lost due to uneven road surfaces, an object in the road or inadequately placed street furniture (Van Elslande and Elvik, 2012). Therefore, motorcycle riders are very vulnerable road users and road accidents involving injuries to them remain a major concern. It is recognised that a concerted effort is required to understand and

70 further improve the safety of motorcyclists (e.g. Morris et al., 2018; https://safe2wheelers.eu).

71 At present, the fatality, serious, and slight, injury risks for motorcyclists are far above the same risks for car users (Nazemetz et al., 2019; MAIDS, 2007; Silla et al., 2018; McCarthy et al., 2005; ERSO Report, 2018). The US study by Nazemetz et al., 2019 reports that motorcycle accident

74 fatalities more than doubled from approximately two thousand per annum in 1996 to about four 
75 and a half thousand per annum in the US in 2014. While during the same time period all traffic

76 fatalities fell from forty thousand to the low thirty thousands per annum. The European report

77 (MAIDS, 2004) involved the collection of motorcycle accident data for five European countries;

78 France, Spain, Germany, Italy and the Netherlands and highlights main accident configurations

79 such as intersections ( $35 \%$ of accidents). The UK study by McCarthy et al. (2005) reports that

80 motorcycle accidents include 'right of way' accidents, accidents involving loss of control on

81 bends, and accidents caused by motorcyclists using the more frequent overtaking and passing

82 opportunities. Following up on these studies which identify high risk situations for motorcyclists

83 the present study examines the effect of speed on outcome once these safety critical encounters

84 involving a motorcycle have taken place.

85 Many studies underline the relationship between speed and road accidents, highlighting issues

86 such as the individual casualty risk of travelling at a certain speed (Kloeden et al., 2002) to

87 accident sensitivity to speed limit changes (Nilsson, 2004; Elvik et al., 2004). These authors

88 indicate that physical principles underlie the speed dependencies observed in their controlled data

89 analyses and resulting models. Nilsson (2004), in describing the power law model relating speed

90 and accident risk and severity refers to the importance of kinetic energy, energy of impact and

91 stopping distance are referred to in Kloeden et al. (2002), and kinetic energy is considered in

92 Elvik et al. (2004) and estimates of stopping distances for different speeds are also provided to

93 compare accident risk. The consequence of speed in an accident has been quantified in terms of

94 vehicle damage energy (e.g. Campbell, 1974; Vangi, 2009); specifically for motorcycles in Vangi

95 and Cialdai (2014), and in powered-two-wheeler/car accident reconstruction in Pierini (2016).

96 Numerous studies also relate speed and injury risk (e.g. Mackay, 2007; Otte et al., 2012; Wisch

97 et al., 2017) and in the context of motorcycle accidents relative speed has been shown to correlate

98 well with injury (Otte et al., 2006; Dinga et al., 2019). 
99 In the present study the contribution of speed in situations, commencing from the reaction 100 location to the safety critical event involving a motorcyclist and resulting in a fatal accident, is

101 considered. The effect of speed on defined accident risk and severity is examined. From the reaction point accident risk is quantified in terms of stopping distance and accident severity is quantified in terms of speed squared. A novel display/parameter space is introduced indicating the variation of speed-squared versus stopping distance from the reaction point to the rest position of the vehicle following braking. The vertical axis represents accident severity (proportional to speed-squared) and the horizontal axis represents accident risk (proportional to stopping distance). The integral of the speed-squared versus stopping distance graph (the area under the speed-squared line is shown to represent overall severity risk - the accident risk weighted by the severity of accident. The methodology allows the accident risk and accident severity dimensions to be analysed and quantified in a direct and unified manner.

\section{Material and methods}

A police database of fifty-one powered two-wheeler (motorcycles and mopeds) accidents which took place between 2010 and 2016 in the West Midlands, UK, is examined. The UK police force completes a collision investigation report for every road traffic accident that involves fatal or lifechanging consequences. A formal collision investigation is typically undertaken by a highly trained collision investigator and a subsequent report is completed. Each report includes detailed information regarding the collision location, the circumstances surrounding the collision, witness statements, vehicle defects and contributory factors which lead to the accident taking place. The police also carry out a series of tests in order to determine the main causes of the accident and which party is believed to be at fault. From the dataset of fifty-one accidents sixteen cases (all involving a motorcycle) are available where the pre-impact vehicle speeds could reasonably be 
estimated using a variety of methods (other than through witness statements) for accidents involving motorcyclists and fatal outcomes; these are the data selected for further analysis.

The sixteen cases with fatal outcomes and estimated speed data comprise a variety of accident configurations summarised in the list below. In all but one accident a motorcyclist was killed. In one case (case 14) a pillion passenger only was fatally injured and, in another case (case 9), a pillion passenger and motorcyclist were fatally injured. The main accident configurations are illustrated in Fig. 1 with accompanying summary descriptions of the configurations provided in Table 1. Each of the sixteen accidents is indexed according to the descriptions in Table 1.

1. Car moves from lane 2 to lane 3. Motorcycle moves rapidly (above the speed limit) from lanes 1 to 2 to 3 . Vehicles simultaneously move into lane 3 resulting in a collision. (Oth - motorcycle weaving in traffic)

2. Car intends to turn right from side road into main road, edging out slowly, motorcycle coming from left brakes heavily and loses control, impacting kerb, sliding along pavement into tree. No actual contact between vehicles. (T11, Oth - loss of control, off roadway to left)

3. The car turns right out of side road into path of motorcycle approaching from the right. Motorcycle moving above speed limit. Car stopped while other vehicles pass. Motorcycle travels 2.7 seconds behind another vehicle prior to collision. (Oth Opponent vehicle turning to the right, crossing the [straight] motorcycle path. Motorcycle is travelling straight, coming from the right side of the opponent vehicle.)

4. Car in filter lane, turns right into side road, impacted by motorcycle travelling above speed limit in the opposite direction. (T8)

5. Van stationary at $\mathrm{T}$ junction, intending to turn right out of side road onto main road. Van commences turn, collides with motorcycle coming (above the speed limit) from 
the right. Motorcycle attempted emergency braking, was upright when colliding with van. (Oth - Opponent vehicle turning to the right, crossing the [straight] motorcycle path. Motorcycle is travelling straight, coming from the right side of the opponent vehicle.)

6. Motorcycle loses control navigating a left-hand bend (travelling above the speed limit), collides head on with slowed car travelling in the opposite direction. Skid marks start at centreline and move to opposing carriageway. (LoCC, Oth - head on collision)

7. Car turns right into driveway across path of motorcycle. Motorcycle travelling above speed limit attempts emergency braking. Motorcycle falls to side and motorcycle and rider slide along carriageway into kerb then car. (T8, Oth - loss of control on roadway)

8. Motorcycle travelling above the speed limit towards junction (along the 'stick' of the T) when the rider loses control, motorcycle slides across the junction and collides with the opposite kerb. No other vehicle. (Oth - missed intersection/end of road, Oth - loss of control on roadway)

9. Other vehicle turning right into side road, motorcyclist travelling in opposite direction. Motorcyclist emergency brakes, skids and slides into the other vehicle. Rider and pillion passenger thrown from motorcycle. (T8)

10. Motorcycle approaches crossroads intending to turn right, waits for light to turn green. Car travelling (above the speed limit) in opposite direction intending to go straight on approaches junction when lights have turned green, goes through without slowing. When lights turned motorcycle had started to turn right, across path of car. (T8)

11. Car turning right into side junction, impacted by motorcycle travelling (above the speed limit) in the opposite direction. Motorcycle overtaking cars. (T8) 
12. Car turning right into premises, struck on offside by motorcycle that was overtaking it. Motorcycle travelling above the speed limit. (Oth - Opponent vehicle turning to the right, crossing the [straight] motorcycle path. Motorcycle is travelling straight in the same direction as the heading of the opponent vehicle and overtaking it.)

13. Car turns right out of side road (performing a U-turn using the side street) into path road) of motorcycle travelling above the speed limit along the carriageway. Car stationary in side road before pulling out. (Oth - manoeuvring - opponent vehicle is U-turning from the right to the left at side street/carriageway intersection. Motorcycle traveling from right on carriageway)

14. Motorcycle accelerates and pillion passenger falls. No other vehicle. (Oth - fall from moving vehicle)

15. Car turned right across the path of a motorcycle. Motorcycle collides with the nearside of the vehicle. Poor weather conditions. Motorcycle moving above the speed limit, car turns across the path of the motorcycle at close range. (T8)

16. The motorcycle travels straight ahead. The car travels in the opposite direction, and makes a right turn manoeuvre. As the car performed this manoeuvre, the rider of the motorcycle applies the brakes and induces a skid. The motorcycle falls to its nearside and slides along the road, before colliding with the front of the car. The rider is thrown clear, colliding with street furniture. (T8, Oth - loss of control on roadway - straight 


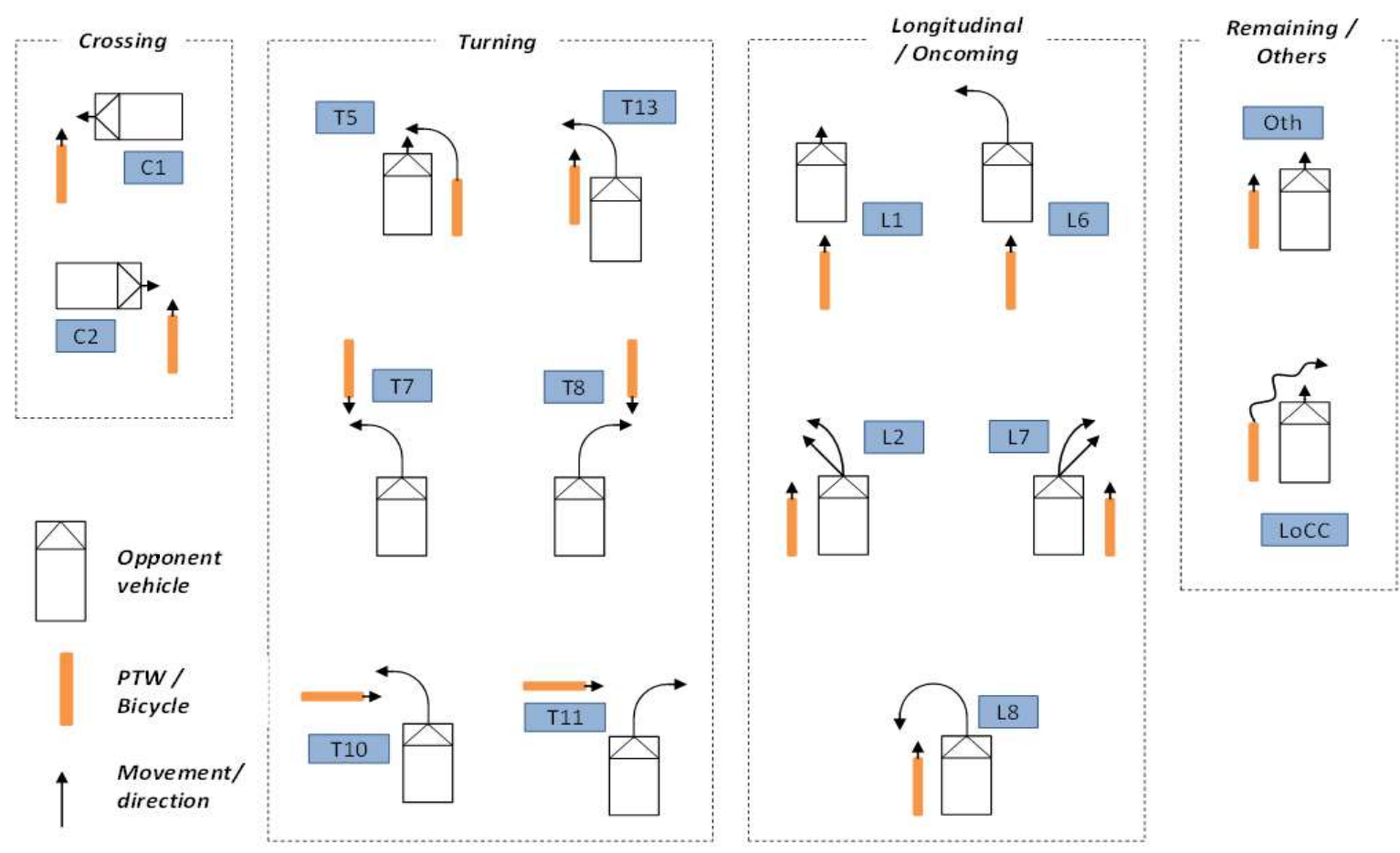

Fig. 1 Accident configuration for motorcycle and opponent vehicle (Morris et al., 2018)

\begin{tabular}{|c|c|}
\hline C1 & $\begin{array}{l}\text { - Motorcycle travelling straight } \\
\text { - Opponent vehicle crossing the motorcycle path from the right side }\end{array}$ \\
\hline C2 & $\begin{array}{l}\text { - Motorcycle travelling straight } \\
\text { - Opponent vehicle crossing the Motorcycle path from the left side }\end{array}$ \\
\hline T5 & $\begin{array}{l}\text { - Motorcycle turning to the left, crossing the (straight) opponent vehicle path } \\
\text { - Opponent vehicle is travelling straight in the same direction as the heading of the } \\
\text { motorcycle before turning }\end{array}$ \\
\hline T7 & $\begin{array}{l}\text { - Opponent vehicle turning to the left, crossing the (straight) motorcycle path } \\
\text { - Motorcycle coming from the opposite direction, travelling straight }\end{array}$ \\
\hline T8 & $\begin{array}{l}\text { - Opponent vehicle turning to the right, crossing the (straight) motorcycle path } \\
\text { - Motorcycle coming from the opposite direction, travelling straight }\end{array}$ \\
\hline T10 & $\begin{array}{l}\text { - Opponent vehicle turning to the left, crossing the (straight) motorcycle path } \\
\text { - Motorcycle is travelling straight, coming from the left side of the opponent vehicle }\end{array}$ \\
\hline T11 & $\begin{array}{l}\text { - Opponent vehicle turning to the right, crossing the (straight) motorcycle path } \\
\text { - Motorcycle is travelling straight, coming from the left side of the opponent vehicle }\end{array}$ \\
\hline T13 & $\begin{array}{l}\text { - Opponent vehicle turning to the left, crossing the (straight) motorcycle path } \\
\text { - Motorcycle is travelling straight in the same direction as the heading of the opponent } \\
\text { vehicle before turning }\end{array}$ \\
\hline L1 & $\begin{array}{l}\text { - Opponent vehicle and Motorcycle travelling in the same direction } \\
\text { - Motorcycle is travelling straight and hit by the opponent vehicle (going straight) from the } \\
\text { rear }\end{array}$ \\
\hline L2 & $\begin{array}{l}\text { - Opponent vehicle and Motorcycle travelling in the same direction } \\
\text { - Opponent vehicle is swerving to the left in front of the Motorcycle and hit by the } \\
\text { motorcycle }\end{array}$ \\
\hline L6 & $\begin{array}{l}\text { - Opponent vehicle and motorcycle travelling in the same direction } \\
\text { - Motorcycle is travelling straight and hit by the opponent vehicle (turning left) from the rear }\end{array}$ \\
\hline L7 & $\begin{array}{l}\text { - Opponent vehicle and motorcycle travelling in the same direction } \\
\text { - Opponent vehicle is swerving to the right in front of the Motorcycle and hit by the } \\
\text { motorcycle }\end{array}$ \\
\hline L8 & $\begin{array}{l}\text { - Opponent vehicle and motorcycle travelling in the same direction } \\
\text { - Opponent vehicle is u-turning from the right to the left in front of the Motorcycle and hit by } \\
\text { the motorcycle }\end{array}$ \\
\hline LOCC & $\begin{array}{l}\text { - The driver of the motorcycle loses the control of his vehicle, in a curve, and crashes into } \\
\text { an opponent vehicle }\end{array}$ \\
\hline
\end{tabular}




\subsection{Parameter Estimation}

202 The key parameters estimated are friction coefficients, vehicle stopping distance and pre-impact speed and distance to collision. The road/tyre friction coefficients are estimated using dedicated accelerometer equipment during re-enactments/tests performed under emergency braking.

Friction coefficients for the road/motorcycle on its side during sliding are also estimated through re-enactment testing and/or through comparison with values stated in the literature for a particular motorcycle model. The stopping distance is comprised of the distance travelled during the braking response time to an incident and the braking distance, and/or sliding distance, if present.

The braking and sliding distances, are estimated from the tyre and slide (motorcycle on its side, and/or motorcyclist clothing) marks on the road, respectively. The braking response distances are estimated taking into consideration results from recent studies (Jurecki and Stańczyk, 2009; Jurecki and Stańczyk, 2014). The distance to collision $(d t c)$ is the distance from the reaction point to the safety critical incident to the impact point. It is typically estimated through calculating the braking distances up to impact and calculating the reaction distance $\left(d_{r}\right)$ at the estimated speed. The $d t c$ is then the sum of the braking distance up to impact and the reaction distance. The $d t c$ can be different if the unexpected event occurs at a location other than the eventual impact location e.g. a car edging out from an intersection initiates an emergency response on the behalf of the motorcyclist. In this case the $d t c$ is the distance from the reaction point (which is located by working back from the beginning of the braking skid mark) to the intersection.

220 As motorcycle crashes have particular characteristics pre-impact speed may be estimated via a variety of methods. Speed estimates are obtained from 
(i) Closed circuit television (CCTV) security camera evidence,

(ii) tyre marks due to braking,

(iii) motorcycle slide marks, (Hague, 2004)

(iv) motorcyclist slide marks, and

(v) pedestrian throw calculations (Otte, 2004; Searle and Searle, 1983).

229 Analysis of vehicle damage can also be informative regarding pre-impact speeds but is more challenging than speed estimation for car to car impacts due to the typically large mass ratio 231 between a motorcycle and other vehicle and the resulting collision dynamics which may 232 redistribute the incoming translational kinetic energy into translational, rotational and projectile components in addition to vehicle damage. Pre-impact speeds are not estimated via damage analysis (as per the method of Vangi and Cialdi, 2016, for example, because the speeds/damage is typically too great) but the damage is recorded in detail in the form of photographic evidence and noted together with other corroborative evidence such as witness statements, when estimating speed.

\subsubsection{Closed Circuit television CCTV security camera}

240 The motorcycle travels past two reference positions (where the distance between the two reference positions is measured at the scene) between (in this case) the recorded times of $15 \mathrm{~s}$ and $17 \mathrm{~s}$. The motorcycle travels the reference distance in 21 frames of the CCTV footage as illustrated below; counting the number of frames provides an estimate of the time taken $\left(t_{e s t}\right)$ to 244 travel the distance $d_{r e f}$ between two reference points, e.g. in Fig. $2 t_{e s t}=21$ frames $/ 25$ frames $/ \mathrm{s}=$ 2450.84 seconds.

$$
d_{\text {ref }}=\text { position } 2-\text { position } 1=45.4 \mathrm{~m}-27.9 \mathrm{~m}=17.5 \mathrm{~m}
$$

$$
v_{\mathrm{est}}=d_{\text {ref }} / t_{\text {est }}=14.7 \mathrm{~m} / 0.84 \mathrm{~s}=17.5 \mathrm{~m} / \mathrm{s}(63 \mathrm{~km} / \mathrm{h}, 39.4 \mathrm{mph})
$$




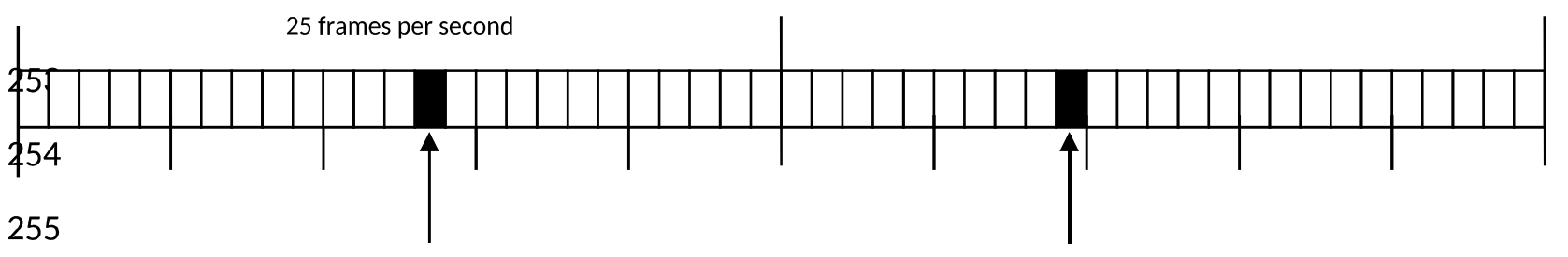

256 Position 125 frames per second $\quad$ Position 2

Fig. 2 Speed estimation using closed circuit television (CCTV) security camera

\subsubsection{Tyre Marks}

262

263 For a motorcycle skidding to a stop under steady braking (constant negative acceleration)

264

$$
v_{d}^{2}=v_{0}^{2}-2 \mu \mathrm{g} d
$$

$v_{0}=$ initial speed

$267 \quad v_{d}=$ speed at distance $d$

$268 \mu=$ coefficient of friction

$269 g=$ acceleration due to gravity

270

271 the final velocity $\left(v_{d f}\right)$ is zero;

272

273

$$
v_{d f^{2}}=v_{0}^{2}-2 \mu \mathrm{g} d
$$

274 Re-arranging Eq. (1) for $\left(v_{0}\right)$ gives:

$$
v_{0}=\sqrt{2 \mu_{\text {skidding }} g d}
$$


2.1.3 Motorcycle slide marks

$$
v_{0}=\sqrt{2 \mu_{\text {sliding }} g d}
$$

2.1.4 Pillion passenger slide

A method for estimating the speed at which a pillion passenger strikes the road when falling off calculation. The estimation is based upon the vertical distance from where the pillion passenger falls from the rear of the motorcycle to the road surface, and the horizontal distance he or she slides along the road surface to a stop (Hague, 2004).

$$
v_{0}=\sqrt{2 \mu_{p} g d}+\mu_{p} \sqrt{2 g h}
$$
where: $v_{0}=$ initial velocity that the pillion passenger strikes the ground

2.1.5 Motorcycle Throw Distance (Searle and Searle, 1983)

$$
v_{\max }=\sqrt{v^{2}+2 \mu g d_{t h}}
$$


300 In the cases examined the speed is estimated by one or more of the various methods above adapted

301 to the specific conditions e.g. friction coefficient for a faired/unfaired motorcycle, gradient etc.

302 The multiple methodologies occasionally revealed valuable additional information e.g. CCTV

303 security camera showing braking lights on over a section of road before tyre skid marks are

304 produced. The methods are combined to provide the most accurate estimates of the speed at the 305 reaction point to the safety critical event.

\subsection{Method}

The method used follows from the theory given in section 3 and is summarized presently.

Stopping distances are estimated based on the pre- incident speed and ignoring the collision position (if any) - i.e. from the reaction point to the safety critical incident to the position the motorcycle would stop if the speed is brought to zero through braking and/or sliding. The stopping distances for the accidents are compared with the stopping distances that would have occurred if the motorcycle was travelling at the speed limit. The stopping distance comparison is considered in the context of the accident risk dimension - the greater the stopping distance (with its starting point measured from the reaction location) the greater the likelihood of an accident occurring. The speed estimate is squared providing a representation of the kinetic energy prior to impact and this is used as an indicator of severity of impact. These estimates are compared to the speed limit squared values which give an indication of the severity of impact if the collision occurred when the motorcycle is travelling at the speed limit. The estimated speed squared values are plotted versus the stopping distances. The area under the curve represents the severity risk (i.e. the sum or integral of the chances of an accident occurring at a given distance from the reaction location multiplied by the severity estimate at that distance). The speed limit values squared are also plotted versus their stopping distances. The area under this curve represents the 
severity risk (i.e. the sum or integral of the chances of an accident occurring at a given instance

326 multiplied by the severity estimate for that instance) if the motorcycle is travelling at the speed

327 limit when the incident response is initiated. Relative severity risks are obtained by calculating

328 the ratio of the areas of the accident estimates to the speed limit estimates.

\begin{tabular}{|c|c|c|c|c|c|}
\hline $\begin{array}{l}\text { Case } \\
\text { Number }\end{array}$ & $\begin{array}{l}\text { Estimated Speed, } v \\
\mathrm{mph}, \mathrm{km} / \mathrm{h} \\
\text { Method }\end{array}$ & $\begin{array}{c}\text { Speed } \\
\text { Limit, } v_{L} \\
\mathrm{mph}, \\
\mathrm{km} / \mathrm{h} \\
\mathrm{m} / \mathrm{s}\end{array}$ & $\begin{array}{l}\text { Friction Coefficient } \\
\qquad \mu(\mathrm{N} / \mathrm{m})\end{array}$ & $\begin{array}{l}\text { Measured Braking Distance } \\
\left(d_{b}\right) \quad \text { Motorcycle Sliding } \\
\text { Distance }\left(d_{s l}\right) \quad \text { and } \\
\text { Throw Distance }\left(d_{t h}\right)(\mathrm{m})\end{array}$ & $\begin{array}{c}\text { Braking } \\
\text { Distance }\left(d_{b}\right) \\
\text { at Speed Limit } \\
(\mathrm{m})\end{array}$ \\
\hline 1 & $\begin{array}{c}47,75.2 \\
20.9 \\
\text { CCTV camera }\end{array}$ & $\begin{array}{c}40,64 \\
17.8\end{array}$ & $\begin{array}{l}0.80 \text { ABS (not used) } \\
0.79 \text { grass/clothing }\end{array}$ & $30.0 d_{t h}$ & $\mathrm{n} / \mathrm{a}$ \\
\hline 2 & $\begin{array}{l}20.9 \\
27,75.2 \\
\text { and motorcycle body marks }\end{array}$ & $\begin{array}{c}30,48 \\
13.3\end{array}$ & $\begin{array}{c}0.68 \text { non-ABS } \\
0.35 \text { faired } \\
\text { motorcycle sliding }\end{array}$ & $\begin{array}{c}26.4 d_{b} \\
11.9 d_{s l} \\
\text { Total distance from } \\
\text { beginning of braking to } \\
\text { collision with tree } \\
50.7 \mathrm{~m}\end{array}$ & 13.3 \\
\hline 3 & $\begin{array}{c}50,80 \\
22.4 \\
\text { CCTV camera }\end{array}$ & $\begin{array}{c}30,48 \\
13.3\end{array}$ & $\begin{array}{c}0.74 \\
\text { de-activated ABS } \\
\text { for test }\end{array}$ & $1.5 d_{b}$ & 12. \\
\hline 4 & $\begin{array}{c}81,129.6 \\
36 \\
\text { CCTV camera }\end{array}$ & $\begin{array}{c}40,64 \\
17.8\end{array}$ & $\begin{array}{l}\text { estimated as } 0.76 \\
\text { de-activated ABS } \\
\text { for test }\end{array}$ & $24.1 d_{b}$ & 21.2 \\
\hline 5 & $\begin{array}{c}55,88 \\
24.4 \\
\text { tyre marks }\end{array}$ & $\begin{array}{c}30,48 \\
13.3\end{array}$ & 0.81 & $37.7 d_{b}$ & 11.1 \\
\hline 6 & $\begin{array}{c}56,89.6 \\
24.9 \\
\text { CCTV camera }\end{array}$ & $\begin{array}{c}30,48 \\
13.3\end{array}$ & $\begin{array}{c}0.68 \\
0.35 \text { fully faired } \\
\text { motorcycle } \\
\text { sliding }\end{array}$ & $\begin{array}{l}10.0 d_{b} \\
22.5 d_{s l}\end{array}$ & 13.3 \\
\hline 7 & $\begin{array}{c}70,112 \\
31.1 \\
\text { tyre and motorcycle body } \\
\text { marks }\end{array}$ & $\begin{array}{c}30,48 \\
13.3\end{array}$ & $\begin{array}{c}0.69 \\
0.36 \text { sliding }\end{array}$ & $\begin{array}{l}15 d_{b} \\
17.5 d_{s l}\end{array}$ & 13.1 \\
\hline 8 & $\begin{array}{c}50,80 \\
22.2 \\
\text { tyre marks }\end{array}$ & $\begin{array}{c}30,48 \\
13.3\end{array}$ & 0.77 & $\begin{array}{c}19.6 d_{b} \\
7 d_{s l}\end{array}$ & 11.7 \\
\hline 9 & $\begin{array}{c}45,72 \\
20 \\
\text { CCTV camera }\end{array}$ & $\begin{array}{c}30,48 \\
13.3\end{array}$ & 0.79 & $12.9 d_{b}$ & 11.5 \\
\hline 10 & $\begin{array}{c}50,80 \\
22.2 \text { (car) } \\
\text { CCTV } \\
\text { slide marks }\end{array}$ & $\begin{array}{c}30,48 \\
13.3\end{array}$ & $\begin{array}{c}0.75 \text { car } \\
0.39 \text { sliding }\end{array}$ & $\begin{array}{l}30.8 d_{t h} \\
45 d_{s l}\end{array}$ & $\mathrm{n} / \mathrm{a}$ \\
\hline $\mathbf{1 1}$ & $\begin{array}{c}80,128 \\
35.8 \\
\text { CCTV camera }\end{array}$ & $\begin{array}{c}30,48 \\
13.3\end{array}$ & $\begin{array}{c}0.74 \\
0.30 \text { sliding }\end{array}$ & $\begin{array}{l}3.8 d_{b} \\
\text { gap } 4.2 \\
25.0 d_{s l}\end{array}$ & 12.2 \\
\hline
\end{tabular}




\begin{tabular}{|c|c|c|c|c|c|}
\hline 12 & $\begin{array}{c}60,96 \\
26.7 \\
\text { CCTV camera re-enactment }\end{array}$ & $\begin{array}{c}30,48 \\
13.3\end{array}$ & 0.75 & $1.6 d_{b}$ & 12.0 \\
\hline 13 & $\begin{array}{c}\text { min. } 42,67.2 \\
18.7 \\
\text { slide displacement }\end{array}$ & $\begin{array}{c}30,48 \\
13.3\end{array}$ & 0.84 & $\begin{array}{c}17.8 d_{b} \\
\text { gap } 6.8 \text { (to impact) }\end{array}$ & 10.7 \\
\hline 14 & $\begin{array}{c}66,105.6 \\
29.5 \text { slide displacement }\end{array}$ & $\begin{array}{c}30,48 \\
13.3\end{array}$ & $\begin{array}{c}0.66 \\
\text { coarse } \\
\text { tarmac/nylon } \\
\text { clothing }\end{array}$ & $54.6^{*}$ & $\mathrm{n} / \mathrm{a}$ \\
\hline 15 & $\begin{array}{c}45,72 \\
20 \text { tyre marks }\end{array}$ & $\begin{array}{c}30,48 \\
13.3\end{array}$ & 0.79 & $25.7 \quad d_{b}$ & $11.5 d_{b}$ \\
\hline 16 & $\begin{array}{c}36,57.6 \\
\begin{array}{c}16.1 \text { tyre marks and slide } \\
\text { displacement }\end{array}\end{array}$ & $\begin{array}{c}20,32 \\
8.89\end{array}$ & $\begin{array}{c}0.73 \\
0.27 \text { sliding }\end{array}$ & $\begin{array}{l}7.2 d_{b} \\
\text { gap } 3.7 \\
14.0 d_{s l}\end{array}$ & $5.5 d_{b}$ \\
\hline
\end{tabular}

Table 2 speed and distance estimates: friction coefficients and distances *distance of pedestrian slide (pillion passenger fall) (n/a - not applicable)

\section{Theory}

As a guide to safe road use the Highway Code - UK, 2017 provides a set of typical stopping distances similar to the stopping distances shown as a function of designated speed limits (20, 30, 40, 50, 60 and $70 \mathrm{mph}$ ) in Fig. 3. The stopping distance comprises the distance travelled during the braking reaction time and the braking distance.

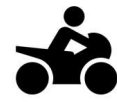

Stopping Distances $(\mathrm{m})$ at the Designated Speed Limits $(\mathrm{m} / \mathrm{s})$

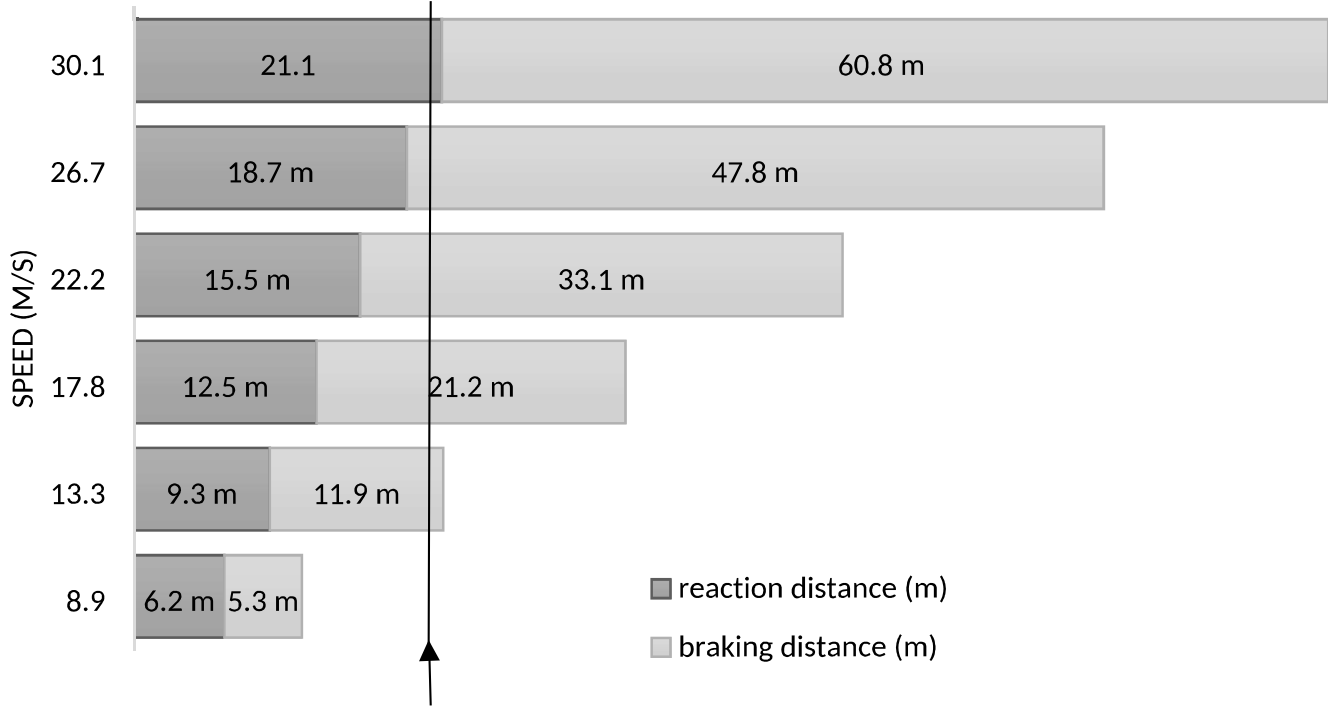

Fig. 3 Motorcycle stopping distances at the designated UK speed limits of 20,30,40,50, 60 and $70 \mathrm{mph}(32,48,64,80,96$ and $112 \mathrm{~km} / \mathrm{h}$ in $\mathrm{m} / \mathrm{s}$ of $8.9,13.3,17.8,22.2,26.7$ and 30.1 ) 
345 A commonly employed temporal metric for assessing collision risk is time to collision, ttc - the 346 time required for two vehicles to collide if they continue at their present speed and on the same 347 path (Hou et al., 2014). Comprehensive studies (Jurecki and Stańczyk, 2009; Jurecki and 348 Stańczyk, 2014) show that the braking response time can be written in terms of the $t t c$ as

$$
t_{r}=0.4 \times t t c+0.3
$$

$t_{r}=$ reaction time, $t t c=$ time to collision

The expression is also consistent with recent findings from a naturalistic study (Markkula et al., 2016) indicating that cognitive load comprises a base processing component and a component dependent on the urgency of the impending critical situation. The immediacy of the situation is 357 determined via visual looming which can be related to ttc (Lee, 1976).

$$
d_{r}=v \times t_{r}
$$

$$
=v \times(0.4 \times t t c+0.3)
$$

$$
=v \times\left(0.4 \times \frac{d t c}{v}+0.3\right)
$$

$$
=0.4 d t c+0.3 v
$$


369 For the purpose of the graph the reaction time (to an emergency situation/traffic event) is 370 estimated at $0.7 \mathrm{~s}\left(t_{r}=0.4 \times t t c+0.3\right)$ with a constant $t t c=1 \mathrm{~s}\left(=\frac{d t c}{v}\right)$, so the distance to the safety

371 critical event increases linearly in direct proportion to the speed.

372

373 e.g. A motorcyclist travelling at $20 \mathrm{mph}$ encounters a conflict situation that necessitates 374 emergency braking

375

376 The speed in SI units $(\mathrm{m} / \mathrm{s})$ is

377

$$
1 \mathrm{mph} \rightarrow \frac{8 \mathrm{~km}}{5 \mathrm{~h}} \rightarrow \frac{8}{5} \times \frac{1000 \mathrm{~m}}{60 \times 60 \mathrm{~s}} \rightarrow 0.444 \frac{\mathrm{m}}{\mathrm{s}}
$$

379

$$
\text { initial speed } v_{0}=20 \mathrm{mph} \rightarrow 20 \times 0.444 \frac{\mathrm{m}}{\mathrm{s}}=8.9 \frac{\mathrm{m}}{\mathrm{s}}
$$

The reaction distance $\left(d_{\mathrm{r}}\right)$ is

$$
d_{r}=v_{0} \times t_{r}=8.9 \frac{\mathrm{m}}{\mathrm{s}} \times 0.7 \mathrm{~s}=6.2 \mathrm{~m}
$$

This is indicated in dark gray in the bottom panel of Fig. 3 .

387 The kinematic equation relating speed under constant negative acceleration due to braking is 388

$$
v^{2}=v_{0}^{2}-2 \mu \mathrm{g} d
$$


391 where $d=$ distance travelled under constant braking from initial point of braking, $v=$ speed at 392 distance $d, v_{0}=$ initial speed, $\mu=$ tyre-road surface friction coefficient, $g=$ acceleration due to 393 gravity

395 As the distance travelled under constant negative acceleration (uniform braking) increases 396 linearly (i.e. as $d$ increases linearly) speed-squared $\left(v_{0}^{2}-v^{2}\right)$ decreases linearly from an initial value 397 of $v_{0}^{2}$

398 Rearranging Eq. (2) in term of distance from the initial point of braking, $d$ gives

$$
d=\left(v_{0}^{2}-v^{2}\right) / 2 \mu \mathrm{g}
$$

401

402 From Eq. (3) it can be seen, if the (initial) speed $\left(v_{0}\right)$ is doubled, the braking distance increases 403 four-fold in bringing the vehicle to rest $(v=0)$.

404

405

406

e.g. A motorcyclist travelling at $20 \mathrm{mph}$ commences full emergency braking

The braking distance (i.e. the distance moved through in reducing the speed from an initial value 407 $v_{0}=8.9 \mathrm{~m} / \mathrm{s}$ to a final value $v=0$ under constant negative acceleration due to braking is, from Eq.

408 (3),

409

410

$$
d=\left[(8.9)^{2}-0^{2}\right] /(2 \times 0.76 \times 9.81)=5.3 \mathrm{~m}
$$

This is indicated in light gray in the bottom panel of Fig. 3.

e.g. A motorcyclist travelling at $40 \mathrm{mph}$ commences full emergency braking

The braking distance is 
This is indicated in light gray in the panel third from bottom of Fig. 3.

421 In the event of a conflict that initiates a full braking response the likelihood of collision is proportional to the stopping distance (which is comprised of the speed dependent reaction distance and the speed-squared dependent braking distance as illustrated in Fig. 3). Therefore, stopping distance is interpreted in terms of the accident risk dimension. The arrow at the bottom of Fig. 3 signifies the location of an unexpected event e.g. a car turning across the path of the motorcyclist at close range. If the motorcyclist is travelling at $20 \mathrm{mph}$ at the reaction point the collision is avoided (the vertical line with the arrow does not pass through the stopping distance indicated for $20 \mathrm{mph}$ - bottom panel). If the motorcyclist's speed is $40 \mathrm{mph}$ a collision occurs (the line with the arrow intersects the stopping distance shown for $40 \mathrm{mph}$ - third panel from bottom). Because an unexpected event can occur at any location beyond the reaction point the relative likelihood of a collision occurring is dependent on the ratio of the stopping distances between the two speeds. The stopping distances themselves change slightly if the distance to the unexpected event changes as the $t t c$ changes.

Eq. (10) can also be interpreted in terms of the magnitude of impact should a collision occur. Multiplying eqtn.10 by $1 / 2 m$ and rearranging speeds on the left-hand side gives the work-kinetic energy theorem [Eq. (12)] 
441 from which the kinetic energy $(1 / 2 \times$ mass $\times$ speed-squared $)$ is specified as a function of braking

442 distance

$$
? ? K=K_{\mathrm{i}}-K(d)=W_{\mathrm{f}}
$$

446 The change in kinetic energy $(? ? K)=$ initial kinetic energy $\left(K_{\mathrm{i}}\right)$ minus the kinetic energy at

447 distance $d$ = work done by the frictional force $W_{\mathrm{f}}$ in reducing the speed from $v_{0}$ to $v$.

449 As speed-squared is directly related to the kinetic energy, which is indicative of the magnitude 450 of impact, it (i.e. speed-squared) is considered in terms of the severity dimension (vertical axis, 451 Fig. 4). Speed-squared is constant throughout the reaction distance and decreases linearly with 452 braking. The arrow in Fig. 4 indicates the location of the unexpected event (the same event as in 453 Fig. 3). The $x$-axis of Fig. 3 contains the same information as Fig. 2; at $20 \mathrm{mph}$ (bottom panel 454 panel 1) a collision does not occur but at $40 \mathrm{mph}$ a collision does occur - following a line 455 vertically upwards from the arrow - it does not intersect panel one but does intersect panel 3. 456 Additionally, in this representation following the line vertically upwards from the arrow it 457 intersects panel 3 (Fig. 4) during the linearly decreasing section. The speed-squared value at this 458 intersection can then be read from the vertical axis, giving an indication of kinetic energy and 459 hence severity of impact. The relative severity at a different speed is determined by comparing 460 its speed-squared value at its point of intersection with the vertical line. 


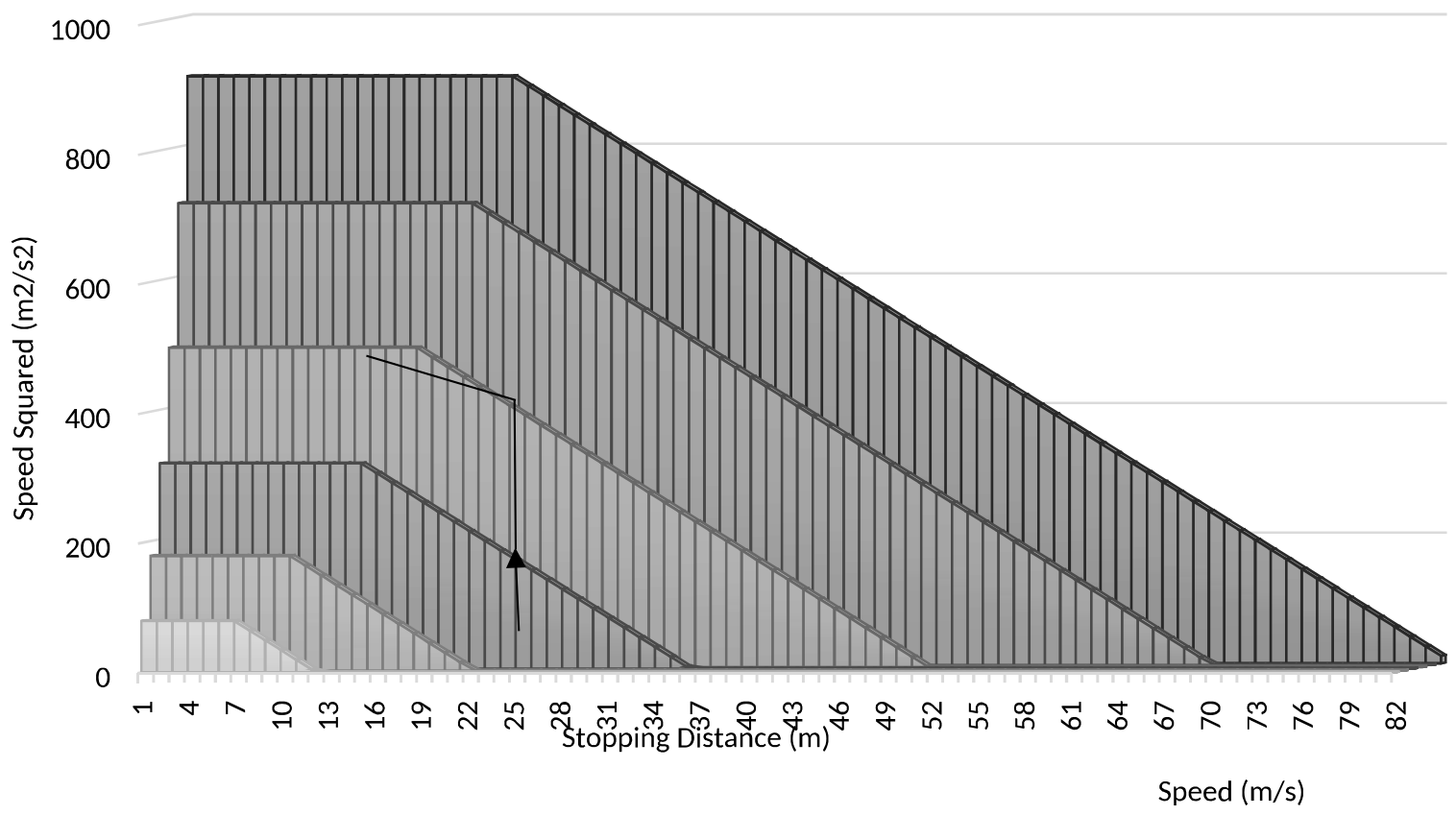

Fig. 4 Speed-squared versus braking distance $d_{b}$ at the designated UK speed limits of $20,30,40,50,60$ and $70 \mathrm{mph}(32,48,64,80,96$ and $112 \mathrm{~km} / \mathrm{h}$ in $\mathrm{m} / \mathrm{s}$ of $8.9,13.3,17.8,22.2,26.7$ and 30.1 )

In summary, Fig. 3 or correspondingly the $x$-axis of Fig. 4 can be used to determine the relative

467 likelihood of a collision occurring at different speeds. Additionally, the vertical axis of Fig. 4 can

468 be used to indicate the severity dimension of impact should a collision occur. Through combining

469 these two dimensions the concept of severity risk is introduced. This is the likelihood of a

470 collision occurring at a given braking distance weighted by the magnitude of the impact should

471 a collision occur at that point. The accident severity risk (ASR) can be estimated from the area

472 under the curve of the speed-squared versus stopping distance graph. It is the sum of the products

473 of severity (the speed-squared magnitude indicated on the vertical-axis) at each location [i.e.

$\left.474 v_{0}^{2}(d)-v^{2}(d)\right]$ multiplied by a measure which is an indicator of the risk of accident - (the stopping

475 distance) at that point $(d)$. The relative accident severity risk (RASR) is the ratio between the

476 areas of speed-squared versus stopping distance for the two different initial speeds. The two 
particular speeds of interest are the estimated speed at the estimated reaction location and the speed limit at this location.

479

\subsection{Calculation}

481

The following parameters are initially estimated for the critical traffic safety incident:

(i) Braking distance up to impact $\left(d_{b i}\right)$, gap, commencement of sliding or coming to a stop

(ii) Distance to collision $(d t c)$

(iii) Reaction distance $\left(d_{r}\right)$

(iv) Total stopping distance $\left(d_{s}\right)$ from reaction point to coming to a stop (ignoring impact)

(v) Speed squared at each distance $d$ during reaction and braking distance phases

(vi) Estimates for (i), (iii), (iv), and (v) at the speed limit keeping the $d t c$ constant

And the following final comparison and estimates are made:

(vii) Compare stopping distance at estimated speed, $d_{s}$, stopping distance at the speed

(x) Estimate RAS = estimated speed squared divided by the speed limit squared 
(xi) Estimate ASR = area under the estimated speed-squared versus stopping distance graph

(xii) Repeat ASR estimate at the speed limit

(xiii) Estimate RASR = area under the estimated speed-squared versus stopping distance graph divided by the area under the speed limit-squared versus stopping distance graph

508

509

A sample calculation illustrates the technique; in this case the motorcycle is travelling straight ahead (green arrow) from the right in the figure and has right of way (ROW) and a car (blue arrow) is making a right turn across the carriageway, to travel in the opposite direction (Fig. 5).

The movement of the road users (manoeuvre of the car, travel of the motorcycle) occurs in a timeframe which gives rise to a critical road safety conflict initiating an emergency braking response on behalf of the motorcyclist. The motorcyclist's pre-braking speed $\left(v_{0}\right)$ is estimated via CCTV at $75 \mathrm{~km} / \mathrm{h}(47 \mathrm{mph}, 20.9 \mathrm{~m} / \mathrm{s})$. His braking distance from initiation of braking up to impact with the car is measured from the tyre skid marks on the road to be $d_{b i}=7.5 \mathrm{~m}$. The impact speed is estimated from Eq. (1) as 


$$
=18.4 \mathrm{~m} / \mathrm{s}
$$

527

528

$$
\text { (and } v_{\mathrm{i}}^{2}=338.6 \mathrm{~m}^{2} / \mathrm{s}^{2} \text { ) }
$$

529
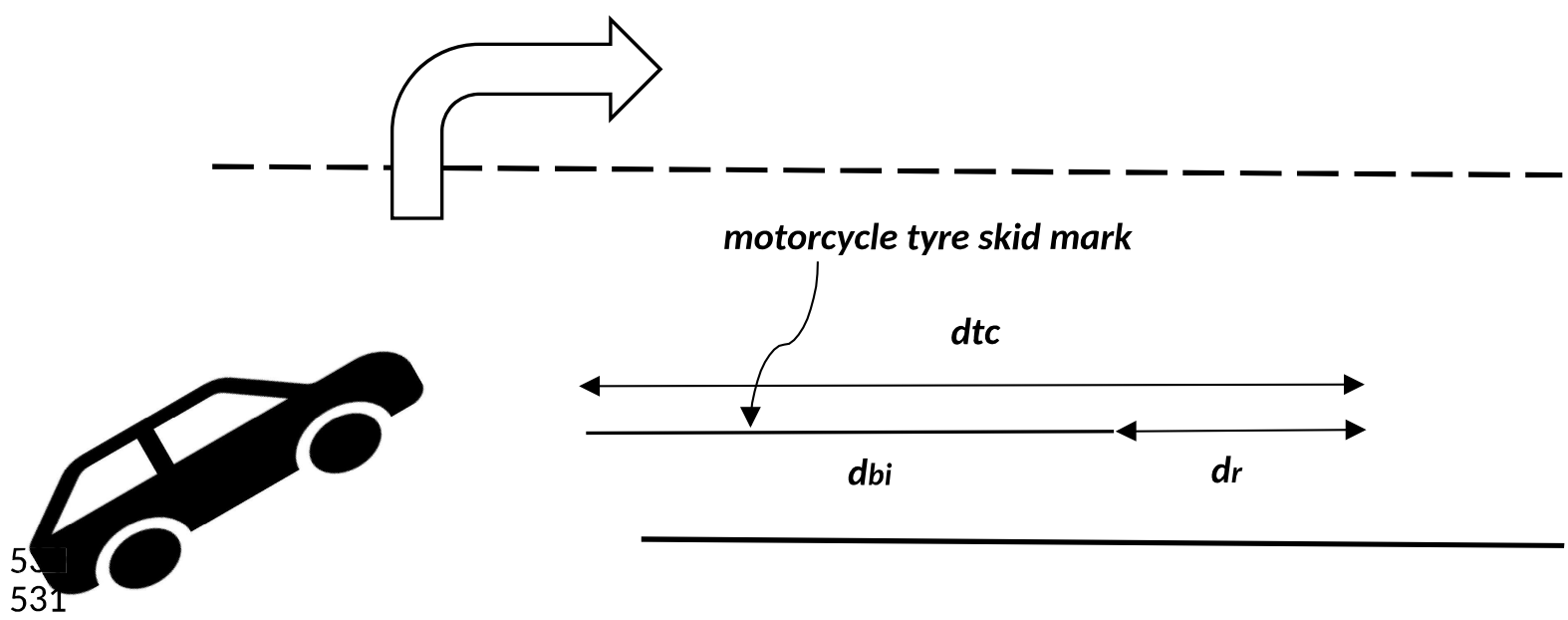

534 To estimate the distance to collision, $d t c$, the braking reaction response distance is added to the

535 braking distance to collision (Fig. 6) :

536

$$
d t c=d_{b i}+d_{r}
$$

538

539 From Eq. (9) $d_{r}=0.4 d t c+0.3 v$, hence

540 


$$
d t c=1.67 d_{b i}+0.5 v=23.0 \mathrm{~m}
$$

546 giving a reaction distance

$$
=15.5 \mathrm{~m}
$$

If the impact had not occurred and the motorcycle came to rest from braking the total braking distance would have been $32.7 \mathrm{~m}$ giving a total stopping distance of $d_{s}=d_{r}+d_{b}=15.5 \mathrm{~m}+37.5$

$\mathrm{m}=53 \mathrm{~m}$. The traffic safety conflict is again considered with the vehicles at the same initial positions (the $d t c$ is the same) but this time the speed of the motorcycle is the speed limit $v_{L}=$

$13.3 \mathrm{~m} / \mathrm{s}$. The above calculations for the speed limit give the values shown in row 3 of Table 3

with row 4 displaying the ratio between all measures at the estimated speed compared to the speed limit.

\begin{tabular}{|c|c|c|c|c|c|c|c|c|c|c|}
\hline & $\begin{array}{l}d_{b i} \\
(\mathbf{m})\end{array}$ & $\begin{array}{l}d t c \\
\text { (m) }\end{array}$ & $\begin{array}{c}d_{r} \\
(\mathbf{m})\end{array}$ & $\begin{array}{c}d_{b} \\
(\mathbf{m})\end{array}$ & $\begin{array}{c}d_{s} \\
(\mathrm{~m})\end{array}$ & $\begin{array}{c}V_{0} \\
(\mathrm{~m} / \mathrm{s})\end{array}$ & $\begin{array}{c}v_{0}^{2} \\
\left(\mathrm{~m}^{2} / \mathrm{s}^{2}\right)\end{array}$ & $\begin{array}{c}V_{i} \\
(\mathrm{~m} / \mathrm{s})\end{array}$ & $\begin{array}{c}v_{i}^{2} \\
\left(\mathrm{~m}^{2} / \mathrm{s}^{2}\right)\end{array}$ & $\begin{array}{c}\text { ASR } \\
\left(\mathrm{m}^{3} / \mathrm{s}^{2}\right)\end{array}$ \\
\hline $\begin{array}{l}\text { Estimated } \\
\text { Speed }\end{array}$ & 7.5 & 23 & 15.5 & 37.5 & 53 & 20.9 & 436.8 & 18.4 & 338.6 & 14960.4 \\
\hline $\begin{array}{l}\text { Speed } \\
\text { Limit }\end{array}$ & 9.8 & 23 & 13.2 & 13.3 & 26.5 & 13.3 & 176.9 & 5.1 & 26.1 & 3246.0 \\
\hline Ratio & 0.77 & 1 & 1.3 & 3.2 & 2.1 & 1.6 & 2.5 & 3.6 & 13.0 & 4.6 \\
\hline
\end{tabular}

Table 3 Distances, speeds, speed squared values and accident severity risk (ASR) at the estimated speed and at the speed limit and their ratios

In Table 3 the ratio in row 4 under stopping distance $=d_{s} / d_{s L}=\mathrm{RAR}$ and the ratio in row 4 under ASR is the RASR.

All estimates are shown on the graph of the severity risk space in Fig. 7. The immediate observation can be made that the $d_{s L}$ is not less than the $d t c$. Hence the collision would have occurred even had the motorcycle been travelling at the speed limit. At the $d t c$ (reading the graph from left to right) the $v_{\mathrm{i}}^{2}$ and $v_{i L}^{2}$ values can be read from the graph (vertical arrow at distance 

magnitude.

574

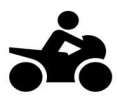

\section{$v$-squared (solid line) and vL-squared (dashed line)} vs stopping distance

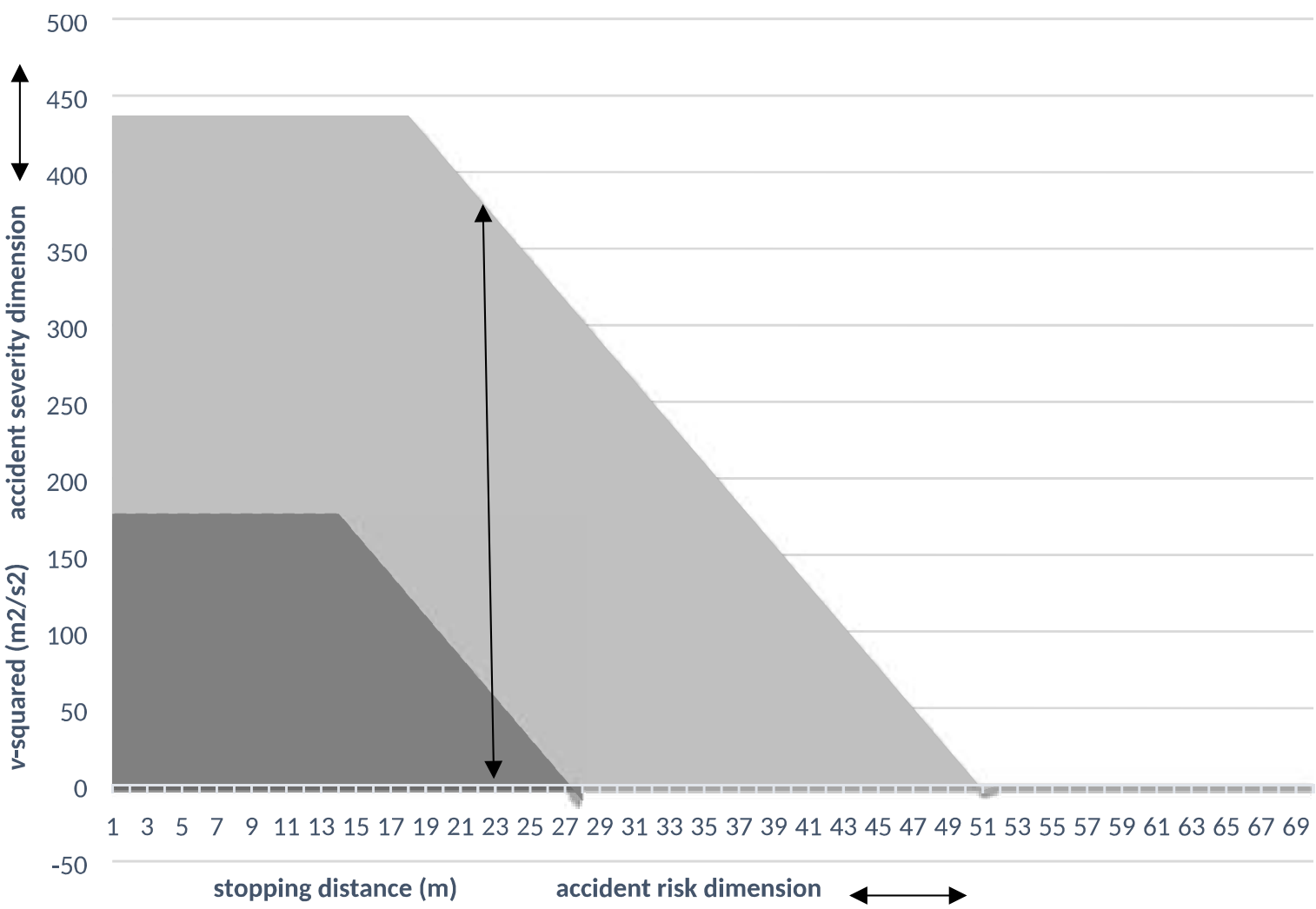

Fig. $7 v$-squared versus braking distance $d_{b}$ when at the speed limit (dark gray) and at twice the speed limit (light gray)

In terms of the general accident risk dimension - the stopping distance is 2.1 times greater and

578 hence there is a 2.1-fold increase in the risk of an impact ( $x$-axis) with any object along the stopping distance to the initial unexpected event at the $d t c$. In terms of the general severity dimension - a measure of the magnitude of impact (in this case the kinetic energy related measure speed-squared) - there is also a 2.5 -fold increase ( $y$-axis). The accident severity risk (ASR) presented i.e. the product of severity (speed-squared magnitude) at each point multiplied by a measure which is an indicator of the risk of accident - (in this case the stopping distance) at that point, is 4.6 times greater at the higher speed. 
The reaction, braking (and gap and sliding if applicable) and stopping distances are estimated via the technique shown in the sample calculation. The stopping distances at the estimated speeds and at the speed limits are shown in the right-hand columns of Table 4. An immediate consideration in term of distances is whether the stopping distance at the speed limit $\left(d_{s L}\right)$ is less than the calculated distance to collision, dtc i.e. would the collision have been avoidable? comparison metric - the ratio of stopping distances (RAR) - ranges from 1.3 to 2.8.

\begin{tabular}{|c|c|c|c|c|c|c|c|}
\hline $\begin{array}{c}\text { Case } \\
\text { Number }\end{array}$ & $\begin{array}{c}\text { Reaction } \\
\text { Distance } \\
\text { at } \\
\text { Estimated } \\
\text { Speed } \\
d_{r}(m)\end{array}$ & $\begin{array}{l}\text { Reaction } \\
\text { Distance } \\
\text { at Speed } \\
\text { Limit } d_{r L} \\
\quad(m)\end{array}$ & $\begin{array}{c}\text { Total } \\
\text { Braking } \\
\text { and/or } \\
\text { Gap } \\
\text { and/or } \\
\text { Sliding } \\
\text { Distance } \\
\text { at } \\
\text { Estimated } \\
\text { Speed } \\
d_{t}(m)\end{array}$ & $\begin{array}{c}\text { Braking } \\
\text { Distance } \\
\text { at Speed } \\
\text { Limit } \\
d_{b L}(\mathrm{~m})\end{array}$ & $\begin{array}{c}\text { Stopping } \\
\text { Distance } \\
\text { at } \\
\text { Estimated } \\
\text { Speed } \\
d_{s}(\mathrm{~m})\end{array}$ & $\begin{array}{l}\text { Stopping } \\
\text { Distance } \\
\text { at Speed } \\
\text { Limit } d_{s L} \\
\text { (m) }\end{array}$ & $\begin{array}{c}\text { Relative } \\
\text { Accident } \\
\text { Risk } \\
\text { RAR } \\
= \\
d_{s} / d_{s L}\end{array}$ \\
\hline 1 & 0 & 0 & 0 & 0 & 0 & 0 & 0 \\
\hline 2 & 25.9 & 23.5 & 50.7 & 13.3 & 76.6 & 36.8 & 2.1 \\
\hline 3 & 12.2 & 9.5 & 34.6 & 12.2 & 46.8 & 21.7 & 2.2 \\
\hline 4 & 34.1 & 28.6 & 86.9 & 21.2 & 121.0 & 49.8 & 2.4 \\
\hline 5 & 37.5 & 34.1 & 37.5 & 11.1 & 75.0 & 45.2 & 1.7 \\
\hline 6 & 34.2 & 30.7 & 46.5 & 13.3 & 80.7 & 44.0 & 1.8 \\
\hline 7 & 37.4 & 31.9 & 72.4 & 13.1 & 109.7 & 45.0 & 2.4 \\
\hline 8 & 28.9 & 26.2 & 32.6 & 11.7 & 61.5 & 37.9 & 1.6 \\
\hline 9 & 18.6 & 16.6 & 25.8 & 11.5 & 44.4 & 28.1 & 1.6 \\
\hline 10 & 0 & 0 & 33.5 & $\mathrm{n} / \mathrm{a}$ & 33.5 & 0 & $n / a$ \\
\hline 11 & 40.0 & 33.2 & 88.3 & 12.2 & 128.3 & 45.4 & 2.8 \\
\hline 12 & 14.4 & 10.4 & 48.4 & 12.0 & 62.8 & 22.4 & 2.8 \\
\hline 13 & 25.8 & 24.2 & 21.2 & 10.7 & 47.0 & 34.9 & 1.3 \\
\hline 14 & 14.8 & 9.9 & 0 & $\mathrm{n} / \mathrm{a}$ & 14.8 & 0 & 0 \\
\hline 15 & 28.4 & 26.4 & 56.1 & 11.5 & 84.5 & 37.9 & 2.2 \\
\hline 16 & 24.7 & 22.5 & 18.1 & 5.5 & 42.8 & 28.0 & 1.5 \\
\hline
\end{tabular}
(RAR)

Table 4 Distances at the estimated speed and the speed limit and the relative accident risk (n/a - not applicable)

A second consideration of immediate concern is if the $d_{s L}>d t c$ what is the resulting impact severity if the motorcycle was travelling at the speed limit compared to the severity of the 
612 documented collision. Table 5 shows that the relative accident severity at impact $\operatorname{RAS}_{\mathrm{i}}\left(v_{i}{ }^{2} / v_{L, i}{ }^{2}\right)$

613 varies from 1.4 to 17.2 (for corresponding speed ratios from 1.2 to 2.3). A more general pre-

614 collision measure of severity is obtained from the Relative Accident Severity RAS $=v^{2} / v_{L}^{2}$.

615 Combining the risk factor - stopping distance and the severity factor - speed squared - gives the

616 relative severity risk measure - the area under the speed squared versus stopping distance graph

617 - which ranges in value from 2.3 to 22.8 for all cases. The severity risk graphs for cases 2 to 9

618 and 11 to 6 are shown in Fig. 8 (cases 1 and 10 had no reaction or braking distances for the

619 motorcyclist). The mode specific vulnerabilities of falling and sliding are readily evident in the

620 graph showing how they give rise to large ASR (area under the curve) and RASR values (when

621 estimating ASR at the speed limit sliding is considered not to have taken place). Large stopping

622 distances of the order of $100 \mathrm{~m}$ to over $230 \mathrm{~m}$ are observed if full sliding takes place. Four out of

623 five of the longer stopping distances involve a prolonged sliding phase. The arrows with numbers

624 indicate the case numbers and their positions signify their impact distances. Fig. 9 illustrates the

625 lower stopping distances, zooming in on cases 2 to 9, 12, 13 and 15. Again sliding, with its lower

626 friction coefficient, typically around 0.3 as compared to 0.75 for normal skidding during braking

627 shows a less steep line and hence a greater ASR (area under the curve).

628 In Fig. 10 the initial speed-squared values are set equal to the same value to allow for a direct

629 comparison of the effect that different friction coefficients (ranging from 0.68 to 0.84 ) have on

$630 d_{s}, v^{2}$ and ASR. The effect on $d_{s}, v^{2}$ and ASR are modest but can be critical.

\begin{tabular}{|c|c|c|c|c|c|c|c|c|c|}
\hline $\begin{array}{l}\text { Case } \\
\text { Number }\end{array}$ & 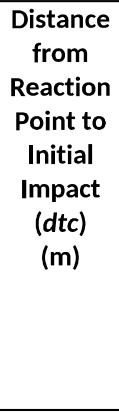 & $\begin{array}{c}\text { Braking } \\
\text { Distance } \\
\text { up to } \\
\text { Impact } \\
\text { at } \\
\text { Speed } \\
\text { Limit } \\
d_{b L, i}(\mathrm{~m})\end{array}$ & $\begin{array}{c}\text { Speed } \\
\text { Squared } \\
\text { at Initial } \\
\text { Impact if } \\
\text { Initially } \\
\text { Moving } \\
\text { at the } \\
\text { Estimated } \\
\text { Speed } \\
v_{i}^{2}\left(\mathrm{~m}^{2} / \mathrm{s}^{2}\right)\end{array}$ & $\begin{array}{l}\text { Speed at } \\
\text { Initial } \\
\text { Impact if } \\
\text { Initially } \\
\text { Moving } \\
\text { at the } \\
\text { Estimated } \\
\text { Speed } \\
V_{i} \\
\text { (mph, } \\
\mathrm{km} / \mathrm{h} \\
\mathrm{m} / \mathrm{s})\end{array}$ & $\begin{array}{c}\text { Speed } \\
\text { Squared } \\
\text { at Initial } \\
\text { Impact if } \\
\text { Initially } \\
\text { Moving } \\
\text { at the } \\
\text { Speed } \\
\text { Limit } \\
v_{i, L}{ }^{2} \\
\left(\mathrm{~m}^{2} / \mathrm{s}^{2}\right)\end{array}$ & $\begin{array}{c}\text { Speed at } \\
\text { Initial } \\
\text { Impact if } \\
\text { Initially } \\
\text { Moving } \\
\text { at the } \\
\text { Speed } \\
\text { Limit } \\
V_{i, L}(\mathrm{~m} / \mathrm{s})\end{array}$ & $\begin{array}{c}\text { Relative } \\
\text { Accident } \\
\text { Severity } \\
v_{i}{ }^{2} / v_{L, i}{ }^{2} \\
\text { at Impact }\end{array}$ & $\begin{array}{c}\text { Estimated } \\
\text { Speed to } \\
\text { Speed } \\
\text { Limit } \\
\text { Ratio } \\
v / v_{L}\end{array}$ & $\begin{array}{c}\text { Relative } \\
\text { Accident } \\
\text { Severity } \\
v^{2} / v_{L}{ }^{2}\end{array}$ \\
\hline 1 & 0 & 0 & 436.8 & $\begin{array}{l}47.0, \\
75.2 \\
20.9\end{array}$ & 316.8 & $\begin{array}{c}40,64 \\
17.8\end{array}$ & 1.4 & 1.2 & 1.4 \\
\hline 2 & 66.2 & 42.7 & 2.9 & $\begin{array}{l}33.8, \\
54.0\end{array}$ & 0 & 0 & $n / a$ & 1.6 & 2.5 \\
\hline
\end{tabular}




\begin{tabular}{|c|c|c|c|c|c|c|c|c|c|}
\hline & & & & 15 & & & & & \\
\hline 3 & 8.8 & 0 & 480.0 & $\begin{array}{l}48.6 \\
77.8 \\
21.6\end{array}$ & 177.8 & $\begin{array}{c}30,48 \\
13.3\end{array}$ & 2.6 & 1.7 & 2.8 \\
\hline 4 & 44.5 & 15.9 & 236.0 & $\begin{array}{c}69.1 \\
110.5 \\
30.7\end{array}$ & 79.8 & $\begin{array}{c}20,32 \\
8.9\end{array}$ & 3.0 & 2.0 & 4.0 \\
\hline $5^{\#}$ & $\mathrm{n} / \mathrm{a}$ & 0 & 0 & 0 & 0 & 0 & $\mathrm{n} / \mathrm{a}$ & 1.8 & 3.3 \\
\hline 6 & 42.6 & 11.9 & 327.7 & $\begin{array}{l}37.6, \\
60.1 \\
16.7\end{array}$ & 19.0 & $\begin{array}{c}10,16 \\
4.4\end{array}$ & 17.2 & 1.9 & 3.5 \\
\hline 7 & 40.4 & 8.5 & 640.5 & $\begin{array}{l}60.1, \\
96.1 \\
26.7\end{array}$ & 62.7 & $\begin{array}{c}18,29 \\
7.9\end{array}$ & 10.2 & 2.3 & 5.4 \\
\hline 8 & 41.1 & 14.9 & 148.6 & $\begin{array}{l}26.6, \\
42.5 \\
11.8\end{array}$ & 0 & 0 & $\mathrm{n} / \mathrm{a}$ & 1.7 & 2.8 \\
\hline 9 & 24.1 & 7.5 & 200.1 & $\begin{array}{l}31.8, \\
50.8 \\
14.1 \\
\end{array}$ & 0 & 0 & $\mathrm{n} / \mathrm{a}$ & 1.5 & 2.2 \\
\hline 10* & 0 & 0 & 492.8 & $\begin{array}{l}49.9 \\
79.9 \\
22.2 \\
\end{array}$ & 177.8 & $\begin{array}{c}30,48 \\
13.3\end{array}$ & 2.8 & 1.7 & 2.8 \\
\hline 11 & 57.1 & 23.9 & 1065.1 & $\begin{array}{c}72.9, \\
116.6 \\
32.4\end{array}$ & 0 & 0 & $\mathrm{n} / \mathrm{a}$ & 2.7 & 7.3 \\
\hline 12 & 10.3 & 0 & 689.4 & $\begin{array}{l}59.2 \\
94.7 \\
26.3\end{array}$ & 94.5 & $\begin{array}{c}22,35 \\
9.7\end{array}$ & 7.3 & 2.0 & 4.0 \\
\hline 13 & 51.9 & 27.7 & 56.3 & $\begin{array}{l}17.1 \\
27.4 \\
7.6 \\
\end{array}$ & 0 & 0 & $\mathrm{n} / \mathrm{a}$ & 1.4 & 2.0 \\
\hline 14 & 0 & 0 & 870.3 & $\begin{array}{c}66.4 \\
106.2 \\
29.5\end{array}$ & 177.8 & $\begin{array}{c}30,48 \\
13.3\end{array}$ & 4.9 & 2.2 & 4.8 \\
\hline 15 & 42 & 15.6 & 1.7 & $\begin{array}{c}2.9,4.7 \\
1.3\end{array}$ & 0 & 0 & $n / a$ & 1.5 & 2.2 \\
\hline 16 & 39.7 & 17.2 & 757.3 & $\begin{array}{c}19.4 \\
31.0 \\
8.6\end{array}$ & 0 & 0 & $\mathrm{n} / \mathrm{a}$ & 1.8 & 3.3 \\
\hline
\end{tabular}

Table 5 distances, speeds, and speed ratios related to impact \#comes to a stop after braking then sliding without hitting another vehicle or object *car speed ( $\mathrm{n} / \mathrm{a}$ - not applicable)

\begin{tabular}{|c|c|c|c|c|c|}
\hline $\begin{array}{c}\text { Case } \\
\text { Number }\end{array}$ & $\begin{array}{c}\text { Estimated } \\
\text { Speed } \\
\text { Squared } \\
\mathbf{v}^{2}\left(\mathbf{m}^{2} / \mathbf{s}^{2}\right)\end{array}$ & $\begin{array}{c}\text { Speed } \\
\text { Limit } \\
\text { Squared } \\
\mathbf{v}_{\mathrm{L}}{ }^{2}\left(\mathbf{m}^{2} / \mathbf{s}^{2}\right)\end{array}$ & $\begin{array}{c}\text { Accident Severity } \\
\text { Risk at the } \\
\text { Estimated Speed } \\
\text { ASR }\left(\mathbf{m}^{3} / \mathbf{s}^{2}\right)\end{array}$ & $\begin{array}{c}\text { Accident Severity } \\
\text { Risk at the Speed } \\
\text { Limit } \operatorname{ASR}_{\mathrm{L}}\left(\mathbf{m}^{3} / \mathbf{s}^{2}\right)\end{array}$ & $\begin{array}{c}\text { Relative } \\
\text { Accident } \\
\text { Severity } \\
\text { Risk } \\
\text { RASR } \\
= \\
\text { ASR/ASR }\end{array}$ \\
\hline $\mathbf{1}$ & 436.4 & 316.8 & 0 & & \\
\hline $\mathbf{2}$ & 436.8 & 177.8 & 22987.9 & 6549.1 & $\mathrm{n} / \mathrm{a}$ \\
\hline $\mathbf{3}$ & 501.8 & 177.8 & 14805.6 & 3853.3 & 3.5 \\
\hline $\mathbf{4}$ & 1296.0 & 316.8 & 100565.7 & 15788.9 & 6.4 \\
\hline $\mathbf{5}$ & 595.4 & 177.8 & 33466.8 & 8028.3 & 4.2 \\
\hline $\mathbf{6}$ & 620.0 & 177.8 & 43879.5 & 7819.6 & 5.6 \\
\hline $\mathbf{7}$ & 967.2 & 177.8 & 89003.6 & 8004.6 & 11.1 \\
\hline $\mathbf{8}$ & 492.8 & 177.8 & 28393.1 & 6738.4 & 4.2 \\
\hline
\end{tabular}




\begin{tabular}{|c|c|c|c|c|c|}
\hline $\mathbf{9}$ & 400.0 & 177.8 & 12617.2 & 4997.5 & 2.5 \\
\hline $\mathbf{1 0}$ & 492.8 & 177.8 & 8254.4 & 0 & $\mathrm{n} / \mathrm{a}$ \\
\hline $\mathbf{1 1}$ & 1267.4 & 177.8 & 183833.8 & 8071.1 & 22.8 \\
\hline $\mathbf{1 2}$ & 712.9 & 177.8 & 27533.6 & 3982.5 & 6.9 \\
\hline $\mathbf{1 3}$ & 349.7 & 177.8 & 16493.0 & 6198.6 & 2.7 \\
\hline $\mathbf{1 4}$ & 256.0 & 79.2 & 0 & 783.3 & 0 \\
\hline $\mathbf{1 5}$ & 400.0 & 177.8 & 225900 & 6731.5 & 3.4 \\
\hline $\mathbf{1 6}$ & 860.4 & 177.8 & 11293.1 & 4982.0 & 2.3 \\
\hline
\end{tabular}

\section{Table 6 speed-squared and accident severity risk (ASR) estimates ASR $=$ area under the curve of the $v^{2}$ versus stopping distance graph (n/a- not applicable)}

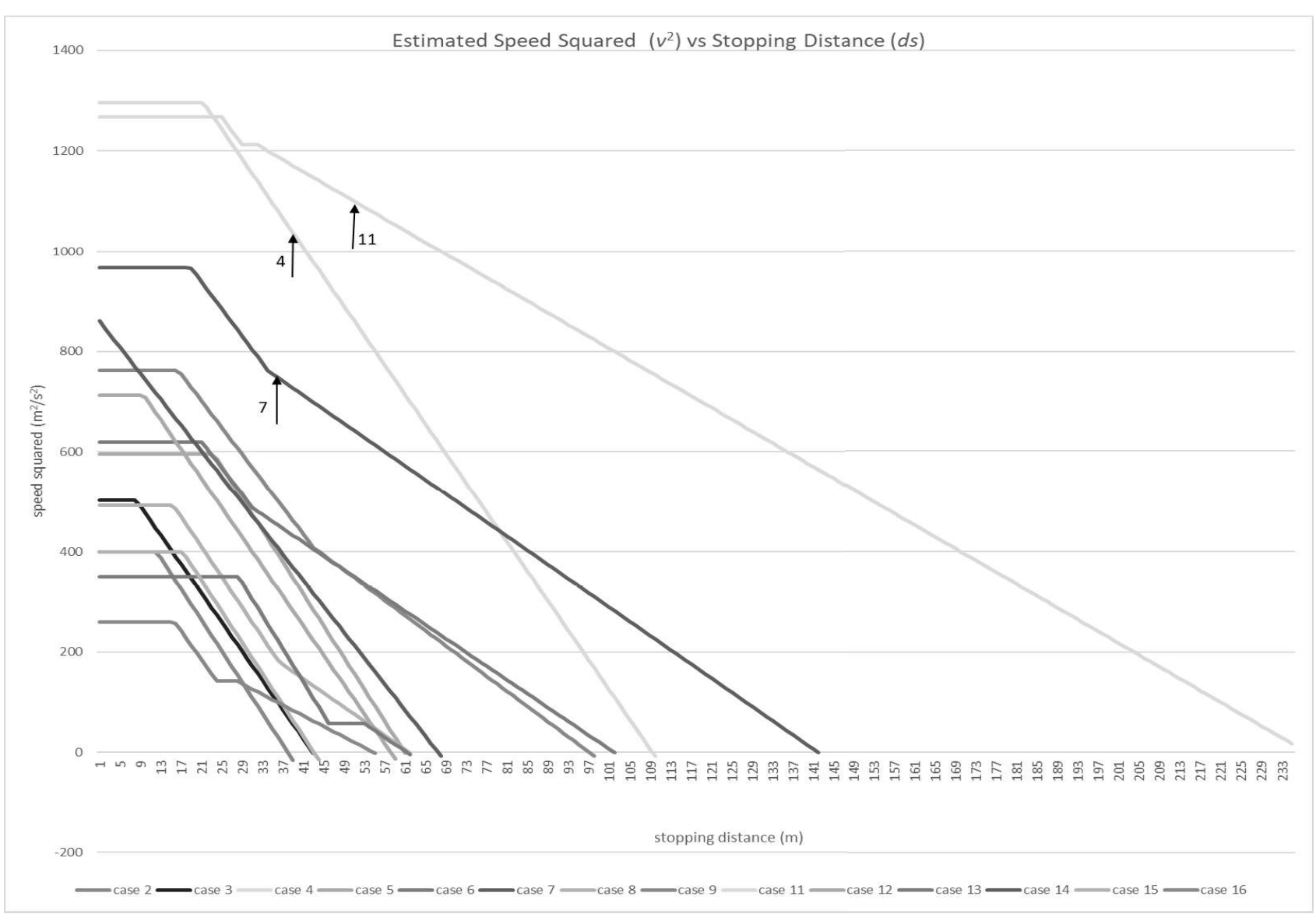

Fig. $8 v$-squared versus stopping distance $d_{s}$ for different friction coefficients for cases 2 to 9 and 11 to 16 , arrows indicate the impact location for case 4, 7 and 11 (the other impact locations are shown, zoomed in, in Fig. 9) 


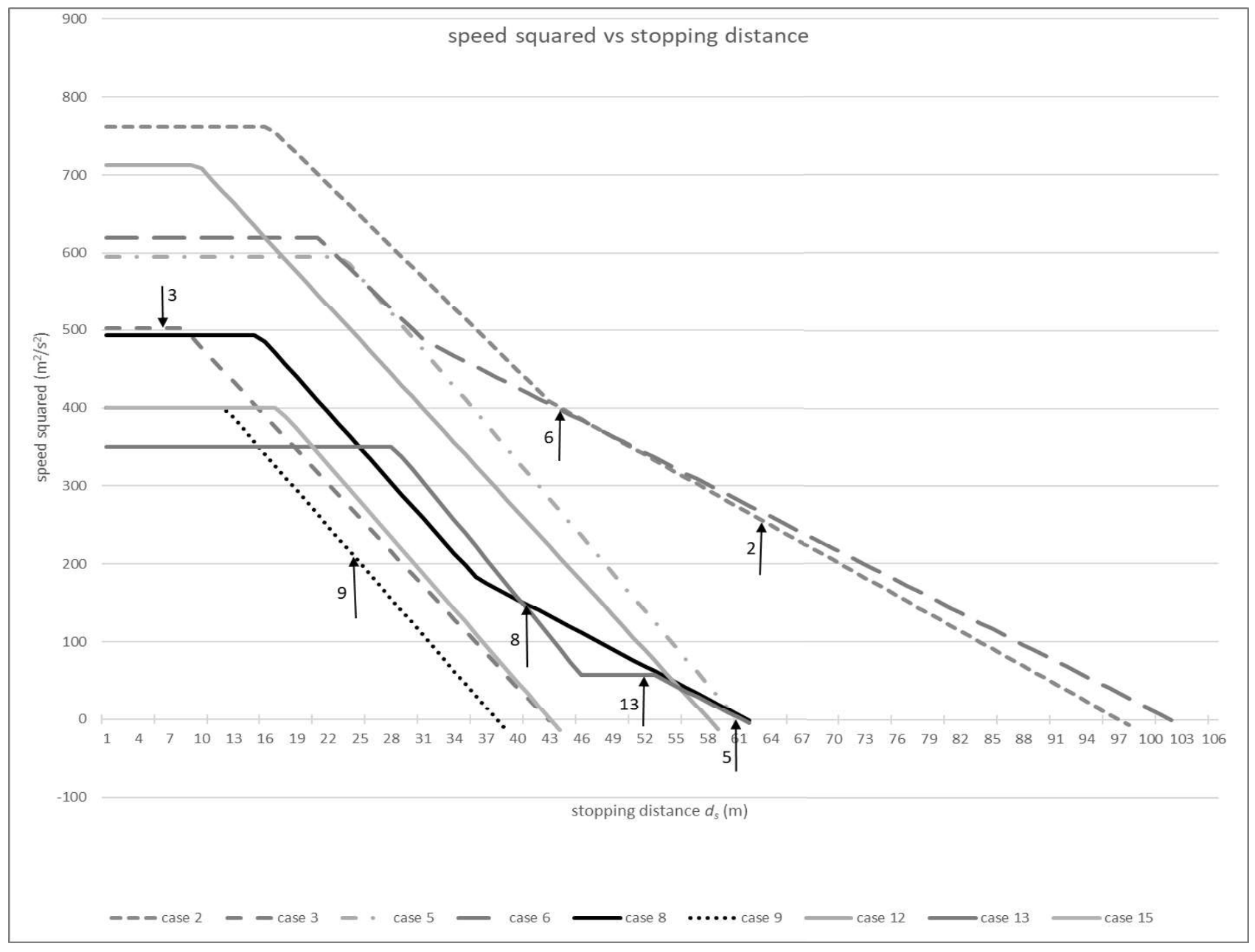

Fig. 9 (Zoomed in section of Fig. 8) v-squared versus stopping distance $d_{s}$ for different friction coefficients for cases 2 to $9,12,13$ and 15 , arrows indicate impact locations in the cases when they occurred

\section{v-squared vs stopping distance for different friction coefficients}

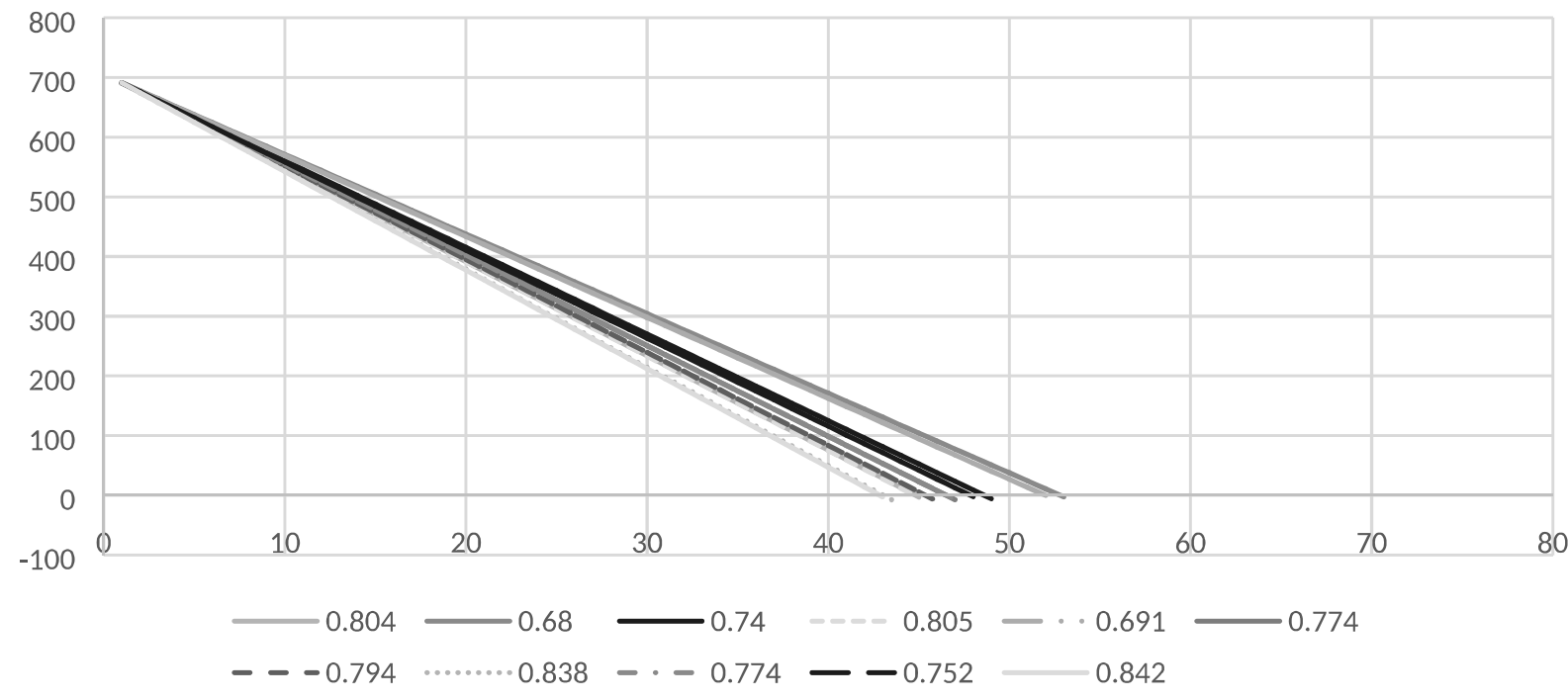

Fig. $10 v$-squared versus braking distance $d_{s}$ for different friction coefficients 
699 Determining the contribution of speed in a road accident, in this case an accident with a fatal 700 outcome involving a motorcycle, is a complex process and involves different stages of 701 consideration. In the present study the accident is analysed from the critical reaction point 702 forward. It does not consider the contribution of speed or other factors in leading to this safety critical situation in the first instance. However, in the process of affording full accountability for speed and other factors in severe and fatal accidents it can be helpful to break the problem down into stages to allow for quantitative analysis. The significance of the theory, analysis and results detailed herein is the provision of quantitative estimates specifying the responsibly of speed in terms of accident risk and accident severity from the critical accident point forward. This allows for the comparison, not of speed values (estimated pre-impact speed and speed limit) but of the physical and physiological consequences of speed values (kinetic energy, braking, sliding and reaction distances), which have speed raised to a power, dependencies. These dependencies are displayed in an easy to interpret space, the severity/risk space, with speed squared plotted on the vertical axis and stopping distance plotted on the horizontal axis. Relative accident risk, severity and severity risk can be read directly from the graph or following basic calculations based on the 714 graph.

715 When comparing an actual documented collision with a fatal outcome with a re-enactment 716 scenario at the speed limit - typically the incidents involve one slowly manoeuvring vehicle and one faster moving vehicle (in all cases but one here the motorcycle is the faster moving vehicle) coming into conflict - an issue of immediate concern is whether the accident would have taken place had the faster moving vehicle been travelling at the speed limit i.e. whether the stopping distance $d_{s L}$ is less than the $d t c$. Therefore, no matter what factors are contributing to the occurrence of the conflict in the first place the contribution of speed to the risk of accident can 
be quantified relative to travelling at the speed limit. The link between stopping distance and speed quantifies the risk of the accident taking place from the reaction point to the safety critical event forwards. The relative accident risk in response to a safety critical situation shows a partial speed dependent reaction phase $\left(0.4 d t c+0.3 v_{0}\right)$ and a speed-squared dependent braking phase $\left(v_{0}^{2} / 2 \mu g\right)$ and ranges from 1.3 to 2.8 times greater. Comparing $d_{s L}$ in column 7 , Table 4 with $d t c$ in column 2, Table 5, it is observed that eight of the accidents would have been avoided had the motorcycle been travelling at the speed limit. Furthermore, in the event that the accident occurs even if the faster moving vehicle was travelling at the speed limit, the difference in impact severity can be compared. Table 5 column shows the Relative Accident Severity at impact $v_{i}{ }^{2} /$ $v_{L, i}{ }^{2}$ ranges from 1.4 to 17.2. There are other kinematic or dynamics variables that could be used for the vertical axis of the $S-R$ graph - the indicator of accident severity. Kinetic energy $\left(1 / 2 m v^{2}\right)$ is the dynamics parameter that most directly informs about vehicle crush $(x)$ and damage energy $\left(1 / 2 k x^{2}\right.$, where $k$ is the vehicle structural stiffness); e.g. doubling the speed-squared value for a vehicle of mass $m$ will double the vehicle damage energy in a head on or fixed barrier collision. Damage energy/crash severity can, in turn, be correlated with biomechanical injury/accident injury severity (MacKay, 2007; Hayes et al., 2018). Injury risk is proportional to accident severity as expressed via the speed-squared measure. Speed squared presents as a convenient parameter for interpreting what the road user is guided by on the one hand - speed signs and speedometer dial, and the consequences of speed in terms of $d_{s}$ ( $v$ and $v$-squared dependency) and kinetic energy ( $v$-squared dependency), on the other hand. Given these power dependencies, and consequences, of speed, it is pertinent to ask are speed indicators the best guides to safety, at least as currently presented? In Table $5 v$-squared is converted back to speed for convenience because this is the parameter that road users are familiar with and are presented with in the car

745 (speedometer) and on the road (road speed signs). Similarly, no matter what factors lead to the 746 traffic safety conflict in the first instance the contribution of speed to impact magnitude can be 
quantified and compared to travelling at the speed limit. The significance of this is underlined by

748 the following consideration; even if the evidence clearly points to a right of way (ROW) violation

749 (for example) by a vehicle moving from a stationary position (as in Fig. 5) leading to an accident

750 the additional contribution of the impact magnitude due to travelling above the speed limit can

751 be quantified for the ROW vehicle. This affords full responsibility for all road users up to the

752 speed limit and full responsibility for travelling over the speed limit. A related scenario for the

753 same road configuration is when the accident would not have taken place if the faster moving

754 vehicle had been travelling at the speed limit at the time of the manoeuvre of the other vehicle

755 (OV). Acknowledging that the manoeuvring vehicle is responsible up to the speed limit of the

756 OV (ROW exists up to the speed limit at best) and that the OV is responsible for its own speed

757 above the speed limit ensures not compensating for speed or underestimating its consequences in

758 such cases.

759 The risk and severity dimensions of accidents can be explored further through the severity-risk

760 space. RASR, combining accident risk and accident severity provides arguably the clearest

761 overall representative indicator of relative road traffic safety due to speed in response to a critical

762 traffic safety conflict. The severity risk graph (Fig. $4 v^{2}$ vs $d_{s}$ ) provides a space to examine,

763 quantify and compare factors that affect accident risk and severity, whether human,

764 environmental or technological. It has a relatively simple form (e.g. compared to $v$ vs $d_{b}$ for

765 example) with a constant straight line of $v_{0}^{2}$ during the braking reaction response distance and

766 interpretation and a linear response $\left(v_{0}^{2}-2 \mu g d_{b}\right)$ during the braking phase.

767 The $S$ - $R$ curve indicates the primacy of response distances - response times reported in recent

768 literature are lower than previously reported, but human response times are slow in terms of the

769 ideal response required for such safety critical incidents. Autonomous vehicles (AV) can provide

770 for much faster response times and it is then expedient to study how the vehicle occupants will

771 react to the quicker vehicle response. 
772 The $S$ - $R$ graph may also contribute towards providing a safety indicator assessment framework

773 for considering technological advances in road user safety; tyre, road surface, ABS, MAEB

774 (Savino et al., 2013) etc. For example, at a given speed, variation in ASR with friction coefficients

775 is shown in Fig. 10; although these changes in ASR are relatively modest (compared to changes

776 in ASR with speed) they may bring crucial benefits. Also, the large increase in $S-R$ space due to

777 sliding (Fig. 8 and Fig. 9) suggests the potential benefits of technology to maintain stability when

778 braking to prevent falling and sliding. The relative benefits of safety technologies can be assessed

779 and prioritised. The space facilitates severity risk assessment of a given variable or attribute while

780 also helping to provide an understanding of the compounding effect of excess speed. There is

781 also complementarity between the present study and studies of forward collision warning (e.g. Li

782 et al., 2018; Tak et al., 2018) : investigation and development of the $S$ - $R$ space in the context of

783 collision warning would benefit from considering the asymmetry of the braking response when

784 accelerating/decelerating (Tak et al., 2018) and the robust assessment (simulated re-enactment)

785 and validation (field operational trials) protocols of $\mathrm{Li}$ et al., 2018.

786 For the cases analysed the typical scenario is a stationary or slowly manoeuvring more massive

787 vehicle (mass of other vehicle $M$, speed of other vehicle $v_{\mathrm{ov}} \approx 0$ ) and a motorcycle plus rider (mass

$788 m$ ) travelling at speed $v$. In these cases the relative velocity between the vehicles $\left(v_{\text {rel }}=v-v_{\mathrm{ov}}\right)$

789 and velocity as measured from the ground, i.e. absolute velocity ( $\left.v_{\text {absolute}}\right)$, are equal or

790 approximately equal. In other cases, where there is a non-zero relative, or closing, speed, the

791 following expression

$$
1 / 2 \mu_{r}\left(v^{2}-v_{O V}^{2}\right)
$$

793 where $\mu_{r}$ is the reduced mass $=M m /(M+m)$,

794 can be used to estimate the damage energy between the vehicles (Schmidt et al., 1998). Case one

795 in the present study involves a situation where a car and motorcycle simultaneously move

796 laterally into the same lane and collide. The resulting vehicle damage is not excessive, but the 
797 motorcycle rider is dislodged and projected forward eventually dissipating his kinetic energy in

798 a resulting collision with street furniture. In all cases studied the collisions involve the

799

800

801

802

803

804 motorcyclist coming to a stop (zero kinetic energy) in a short time interval. From this point of view, it is expedient to consider absolute kinetic energy as measured with respect to a ground observer as well as noting the energy as per Eq. (15) when the initial impact occurs at a relative velocity. Eq. (15) does not indicate in what proportion the damage energy is shared between the vehicles.

The $S-R$ curves are fully valid for the moment of reaction to the conflict at distance $d t c$ i.e. the response at any distance $d$ is as shown on the graph for an unexpected event at distance $d t c 1$. However, using the same graph if the $d t c$ is shifted to $d t c 2$ (say to the right by an amount ??d), the reaction distance changes by an amount $0.4 \times ? ? d$ also and hence $d_{s}$ increases by $0.4 \times ? ? d$ and ASR increases by $0.4 \times ? ? d \times v^{2}$. The $v$-squared response at any distance $d$ can be estimated from the original graph (for $d t c 1$ ) but now reading the speed-squared value for distance $d$ at the value $d-0.4 \times ? ? d$

The speed-squared dependent accident severity measures range from 1.4 to 7.1 pre-impact and from at impact. The relative accident severity risk shows speed squared to speed cubed dependency components during the reaction phase and a speed to the power of four dependent braking phase and ranges from 2.3 to 22.8 times greater. The measures provide comparative values that reflect relative accident, risk, severity and severity risk for travelling at a given speed compared to travelling at the speed limit i.e. compared to the maximum allowed value for the road section. As it is also important for road users to exercise caution the speed limits are only guides towards safe speeds under certain conditions. It can also be beneficial to specify limits when conditions deteriorate to maintain an equal severity risk. The severity-risk space can be examined to quantify the variable conditions e.g. change in weather - friction coefficient changes 
821 due to rain, ice (change in slope of braking portion of graph), and consequent stopping distance 822 change.

823 The development and application of the methodology supports the power model (Nilsson, 2004;

824 Elvik et al., 2004) relating average speed of traffic to road accident occurrence and severity. It 825 suggests, together with the original studies (Nilsson, 2004; Elvik et al., 2004), that there is a 826 strong physical basis for the power model. Because the power model is based on analysis of data 827 for average traffic speeds (e.g. when two different speed limits have been in place on the same 828 road section) the resulting power exponents also include what effect speed may have in leading 829 to safety critical conflicts in the first instance and what effect it may have on modifications in 830 traffic flow. Comparison of purely physically based approaches complements the use of the 831 power model, and when used in conjunction with the power model, has potential to provide 832 further insight into conflict occurrence and traffic flow effects.

833 Future work will examine the collision process in more detail, considering vector and momentum 834 aspects to trace how the initial kinetic energy (and hence speed) of each vehicle contributes to 835 the eventual outcomes for each road user. Methods to further quantify the braking response and 836 other emergency manoeuvres will be considered together with studies of correlations between 837 injury severity and accident severity.

10 Conclusions

- A framework for analysing the accident risk and severity dimensions of road user accidents at the reaction point to the critical road safety conflict is established.

- A speed-squared (severity dimension) versus stopping distance (risk dimension) parameter space is introduced. Accident severity risk is defined as the integral of speed- 
squared over the stopping distance providing an indication of accident risk weighted by the severity of that risk.

- The accident risk (stopping distance) comprises a speed independent reaction phase component and a speed (to the power of one) reaction phase dependent component followed by a speed-squared dependent braking phase component.

- The accident severity risk which indicates accident risk (stopping distance) weighted or multiplied by severity (speed-squared) is hence comprised of speed to the power of, two, three and four, components.

- The defined accident measures, accident risk, accident severity and accident severity risk are provided in terms relative to values estimated for a vehicle travelling at the speed limit at the safety critical event. The measures are estimated for sixteen fatal accidents from a police dataset of UK motorcycle accidents.

- The vehicle speeds at the critical incident are calculated to be from 1.3 to 2.7 times the speed limit and the values of the corresponding relative accident risks, relative accident severities and relative accident severity risks are estimated to range from 1.3 to $2.8,1.4$ to 7.3 , and 2.3 to 22.8 , respectively.

- The speed-squared versus stopping distance domain is shown to be convenient for interpreting and quantifying accident risk and severity, highlighting the acute consequence of speed on the risk of severe accident.

\section{Acknowledgement}

866 The data used in this study were collected as part of a study funded by the European Commission.

867 The full study report can be found at the following; https://op.europa.eu/s/nqp8

868 The information and views set out in this study are those of the authors and do not necessarily reflect the official opinion of the Commission. The Commission does not guarantee the accuracy 
870 of the data included in this study. Neither the Commission nor any person acting on the

871 Commission's behalf may be held responsible for the use which may be made of the information

872 contained therein.

873 The first author has benefited from participation in the EU COST ACTION TU1407

874 (https://safe2wheelers.eu) between 2015 and 2019.

875

876 Declaration of Interest

877 'Declarations of interest: none'

\section{$878 \quad$ References}

879 Campbell, K.E., 1974. Energy basis for collision severity, SAE Technical Paper 740565.

880 Dinga, C., Rizzi, M., Strandrothc, J., Sanderd, U., Lubbee, N., 2019. Motorcyclist injury risk as a function of real-

881 life crash speed and other contributing factors. Accident Analysis and Prevention 123, 374-386.

882 Dischinger, P.C., Ryb, G.E., Ho, S.M., Braver, E.R., 2006. Injury patterns and severity among hospitalized 883 motorcyclists: a comparison of younger and older riders. Annu Proc Assoc Adv Automot Med. 50, $237-249$.

884 Elvik, R., Christensen, P., Amundsen, A., 2004. Speed and road accidents: An evaluation of the Power Model.

885 Report 740, Institute of Transport Economics, 2004, Oslo, Norway.

886 ERSO Report, 2018. Traffic safety basic facts on motorcycles and mopeds, European Commission, Directorate 887 General for Transport. (www.erso.eu)

888 Hague, D., 2004. Calculation of speed from motorcycle slide marks. Impact 13(1), 10-6.

889 Hayes, W.C., Erickson, M.S., Power, E.D., 2007. Forensic injury biomechanics. Annu. Rev. Biomed. Eng. 9, 5589086

891 Highway Code - UK, 2017. https://www.highwaycodeuk.co.uk/download-pdf.html

892 Hou, J., List, G.F., Guo, X., 2014. New algorithms for computing the time-to-collision in freeway traffic.

893 Simulation Models Computational Intelligence and Neuroscience Article ID 761047, 8 pages

894 http://dx.doi.org/10.1155/2014/761047

895 Jurecki, R., Stańczyk, T.L., 2009. Driver model for the analysis of pre-accident situations. Vehicle System Dynamics $896 \quad 47: 5,589-612$. 
Jurecki, R.S., and Stańczyk, T.L., 2014. Driver reaction time to lateral entering pedestrian in a simulated crash traffic situation. Transp. Res. Part F Traffic Psychol. Behav. 27, 22-36.

899 Kloeden C.N., McLean A.J. and Glonek, G., 2002. Reanalysis of travelling speed and the risk of crash

900 involvement in Adelaide South Australia. Report No. CR 207, Australian Transport Safety Bureau,

901 Canberra, Australia.

902 Lee, D.N., 1976. A theory of visual control of braking based on information about time-to-collision. Perception $9035(4), 437-459$.

904 Li, Y., Zheng, Y., Wang, J., Kodaka, K., Li, K., 2018. Crash probability estimation via quantifying driver hazard 905 perception. Accident Analysis and Prevention. 116, 116-125.

906 Mackay, M., 2007. The increasing importance of the biomechanics of impact trauma. Sadhana 32(4), 397-408.

907 MAIDS, 2004. Motorcycle accident in depth study http://www.maids-study.eu/

908 Markkula, G., Engström, J., Lodin, J., Bärgman, J., Victor, T., 2016. A farewell to brake reaction times? kinematics909 dependent brake response in naturalistic rear-end emergencies Accident Analysis and Prevention 95, 209-226.

910 McCarty, M.G., Walter, L.K., Hutchins R., Tong, R., Keigan, M., 2007. Comparative study of motorcycle accident 911 data from OTS and MAIDS. TRL Published Project Report PPR168.

912 Morris, A.P., Brown, L.A., Thomas, P., Davidse, R.J., Phan, V., Margaritis, D., Usami, D., Robibaro, M., Krupińska,

913 A., Sicińska, K., Ziakopoulos, A., Theofilatos, A., Yannis, G., 2018. Saferwheels study on powered two-wheeler 914 and bicycle accidents in the EU final report. European Commission Contract no. MOVE/C4/2014-661-2

915 Nilsson, G., 2004. Traffic safety dimensions and the Power Model to describe the effect of speed on safety.

916 Bulletin 221, Lund Institute of Technology, Department of Technology and Society, Traffic Engineering, Lund, 917 Sweden.

918 Nazemetz, J.W., Bents, F.D., Perry, J.G., Thor, C., Mohamedshah, Y.M. (2019), “Motorcycle crash causation study: 919 final report" USDOT Report No. FHWA-HRT-18-064.

920 Otte, D., Jänsch, M., Haasper, C., 2012. Injury protection and accident causation parameters for vulnerable road 921 users based on German In-Depth Accident Study GIDAS. Accident Analysis and Prevention, 44(1), 149-153.

922 Otte, D., 2006. Technical parameters for determination of impact speed for motorcycle accidents and the 923 importance of relative speed on injury severity. SAE Technical Paper 2006-01-1562.

924 Otte, D., 2004. Use of throw distances of pedestrians and bicyclists as part of a scientific accident reconstruction 925 method. SAE Technical Paper 2004-01-1216. 
Pierini, M., 2016. Ptw-to-car crash: Piaggio Beverly vs Honda CRV. Preconference Workshop on Crash

https://safe2wheelers.eu

Savino, G., Giovannini, F., Baldanzini, N., Pierini, M., Rizzi, M., 2013. Assessing the Potential Benefits of the

Motorcycle Autonomous Emergency Braking Using Detailed Crash Reconstructions. Traffic Injury Prevention 14(sup1), S40-S49.

932 Schmidt, B.F., "Rusty" Haight, W.R., Szabo, T.J., Welcher, J.B., 1998. System-based energy and momentum analysis of collisions. SAE Technical Paper 980026.

934 Searle, J., Searle, A., 1983. The trajectories of pedestrians, motorcycles, motorcyclists, etc., following a road accident. SAE Technical Paper 831622.

936 Silla, A., Leden, L., Rama, P., Scholliers, J., van Noort, M., Morris, A., Hancox, G., Bell, D., 2018. A headway to improve PTW rider safety within the EU through three types of ITS, European Transport Research Review, 10: 18.

938 Stutts, J., Foss, R., Svoboda C., 2004. Characteristics of older motorcyclist crashes. Annu Proc Assoc Adv Automot Med. 48, 197-211.

940 Summala, H., 2010. Brake Reaction Times and Driver Behavior Analysis. Transportation Human Factors 2(3), 217226.

942 Tak, S., Kim, S., Yeo, H., 2018. A comparison analysis of surrogate safety measures with car-following perspectives

943 for advanced driver assistance system. Journal of Advanced Transportation 2018, Article ID 8040815, 14 pages.

944 Van Elslande, P., Elvik, R., 2012. Powered two-wheelers within the traffic system. Accident Analysis and Prevention 945 $49,1-4$.

946 Vangi, D., 2009. Simplified method for evaluating energy loss in vehicle collisions. Accident Analysis and Prevention 41(3), 633-641.

948 Vangi, D., Cialdai, C., 2014. Evaluation of energy loss in motorcycle-to-car collisions. Int. J. Crashworthiness, 19(4), $949 \quad 361-370$.

950 Wisch, M., Lerner, M., Vukovic, E., Hynd, D., Fiorentino, A., Fornells, A., 2017. Injury patterns of older car 951 occupants, older pedestrians or cyclists in road traffic crashes with passenger cars in Europe - results from 952 SENIORS. In: Proceedings IRCOBI conference, Paper No. IRC-17-17, Antwerp, Belgium, 2017. 
Peter Murphy: Conceptualization, Methodology, Formal Analysis, Writing- Original draft preparation, Writing- Reviewing and Editing

Andrew Morris: Resources, Data Curation, Writing- Reviewing and Editing 